Cite this: Phys. Chem. Chem. Phys. $2014,16,1617$

Received 30th August 2013, Accepted 13th November 2013

DOI: $10.1039 / c 3 c p 53683 a$

www.rsc.org/pccp

\section{Probing the electronic and geometric structure of ferric and ferrous myoglobins in physiological solutions by Fe K-edge absorption spectroscopy $\dagger$}

\author{
Frederico A. Lima, $\ddagger^{a}$ Thomas J. Penfold, ${ }^{\text {abc }}$ Renske M. van der Veen, $\S^{a}$ \\ Marco Reinhard, ${ }^{a}$ Rafael Abela, ${ }^{C}$ Ivano Tavernelli, ${ }^{\mathrm{b}}$ Ursula Rothlisberger, ${ }^{\mathrm{b}}$ \\ Maurizio Benfatto, ${ }^{d}$ Christopher J. Milne ${ }^{a}$ and Majed Chergui ${ }^{a}$
}

\begin{abstract}
We present an iron K-edge $\mathrm{X}$-ray absorption study of carboxymyoglobin ( $\mathrm{MbCO}$ ), nitrosylmyoglobin $(\mathrm{MbNO})$, oxymyoglobin $\left(\mathrm{MbO}_{2}\right)$, cyanomyoglobin $(\mathrm{MbCN})$, aquomet myoglobin (metMb) and unligated myoglobin (deoxyMb) in physiological media. The analysis of the XANES region is performed using the full-multiple scattering formalism, implemented within the MXAN package. This reveals trends within the heme structure, absent from previous crystallographic and X-ray absorption analysis. In particular, the iron-nitrogen bond lengths in the porphyrin ring converge to a common value of about $2 \AA$, except for deoxyMb whose bigger value is due to the doming of the heme. The trends of the $\mathrm{Fe}-\mathrm{N}_{\varepsilon}$ (His93) bond length is found to be consistent with the effect of ligand binding to the iron, with the exception of $\mathrm{MbNO}$, which is explained in terms of the repulsive trans effect. We derive a high resolution description of the relative geometry of the ligands with respect to the heme and quantify the magnitude of the heme doming in the deoxyMb form. Finally, time-dependent density functional theory is used to simulate the pre-edge spectra and is found to be in good agreement with the experiment. The XAS spectra typically exhibit one pre-edge feature which arises from transitions into the unoccupied $d_{\sigma}$ and $\mathrm{d}_{\pi}-\pi_{\text {ligand }}{ }^{*}$ orbitals. 1s $\rightarrow \mathrm{d}_{\pi}$ transitions contribute weakly for $\mathrm{MbO}_{2}$, metMb and deoxyMb. However, despite this strong Fe d contribution these transitions are found to be dominated by the dipole (1s $\rightarrow 4 p$ ) moment due to the low symmetry of the heme environment.
\end{abstract}

\section{Introduction}

The small protein myoglobin (Mb), consisting of a single polypeptide chain of 153 amino acid residues and a heme group, plays a central role in many biological processes by acting as a

\footnotetext{
${ }^{a}$ École Polytechnique Fédérale de Lausanne, Laboratoire de Spectroscopie Ultrarapide, ISIC, FSB-BSP, CH-1015 Lausanne, CH, Switzerland. E-mail: majed.chergui@epfl.ch

${ }^{b}$ École Polytechnique Fédérale de Lausanne, Laboratoire de Chimie et Biochimie Computationnelles, ISIC, FSB-BSP, CH-1015 Lausanne, CH, Switzerland

${ }^{c}$ SwissFEL, Paul Scherrer Inst, $\mathrm{CH}-5232$ Villigen, $\mathrm{CH}$, Switzerland

${ }^{d}$ Laboratori Nazionali di Frascati, Istituto Nazionale di Fisica Nucleare, CP13, 00044 Frascati, Italy

$\dagger$ Electronic supplementary information (ESI) available: A description of the preparation of the myoglobins, the experimental setup, the computational details and supplementary results for $\mathrm{MbCO}, \mathrm{MbO}_{2}$ and metMb. See DOI: 10.1039/ c3cp53683a.

¥ Current address: Centro Nacional de Pesquisa em Energia e Materiais, Brazilian Synchrotron Light Laboratory - LNLS, CP 6192, 13084-971 Campinas, SP, Brazil. $\S$ Current address: Max Planck Institute for Biophysical Chemistry Am Faßberg 11, 37077 Göttingen, Germany.

I Current address: SwissFEL, Paul Scherrer Inst, CH-5232 Villigen, CH, Switzerland.
}

typical heme-based sensor ${ }^{1,2}$ for diatomic molecules that are either toxic (e.g. $\left.\mathrm{CN}^{-}\right)$and/or crucial for survival (e.g. $\left.\mathrm{O}_{2}, \mathrm{NO}\right){ }^{3}$ While the storage and diffusion of $\mathrm{O}_{2}$ is the role most commonly associated with $\mathrm{Mb}$, recent investigations have also implicated its role as a scavenger of nitric oxide. ${ }^{4-6}$ The heme (see Fig. 1), where binding occurs, is linked to the protein by a covalent bond from the iron atom to an imidazole nitrogen $\left(\mathrm{N}_{\varepsilon}\right)$ of the proximal histidine (His93). The ligand (if present) binds on the distal side of the heme and is located close to, but not bonded, to another histidine (His64). The effect of non-covalent and dispersion interactions $^{7}$ between the ligand and His64 can contribute significantly to the reactivity of the active site and is best illustrated by the differences between $\mathrm{CO}$ and $\mathrm{O}_{2}$ binding. In this case, changes in the protein's ligand affinity are initiated by the ability of His64 to provide a hydrogen bond to the ligand which stabilizes $\mathrm{O}_{2}$ more than $\mathrm{CO}^{8-11}$

The description of the biological functions of $\mathrm{Mb}$ relies largely on the use of static protein structures from crystallography, which provide the basic input data to develop a mechanistic understanding. Alternatively, a goal of modern structural biology is the ability to observe biological functions as they evolve in 


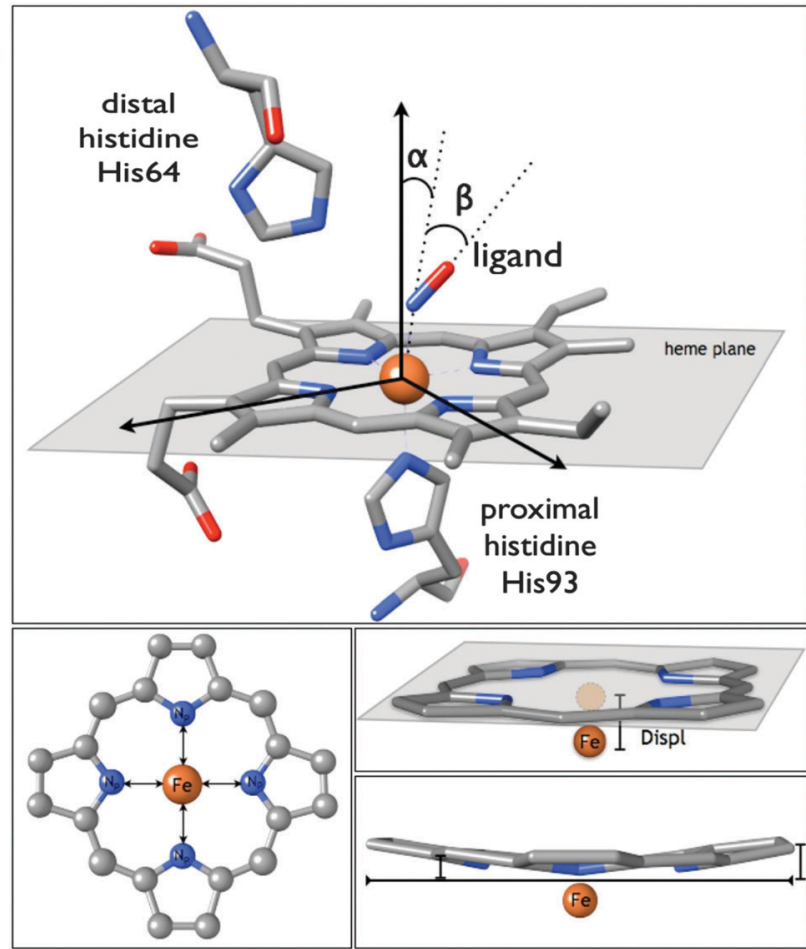

Fig. 1 Schematics of the active center of myoglobin and the relevant parameters used in the fits of the XAS using the MXAN code. The upper panel shows the heme plane and angles $(\alpha$ and $\beta)$ describing the ligand binding geometry. The lower left panel shows the Fe $-\mathrm{N}_{\mathrm{p}}$ distance and the lower right panels show the heme doming parameters.

real time and therefore to fully understand the relationship between structural and dynamical properties, one must achieve not only high spatial resolution, but also a sufficiently high temporal resolution. ${ }^{12-14}$ Important in the context of these studies is that hemoproteins are photosensitive, leading to a wide range of time-resolved optical and X-ray spectroscopic studies ranging from milliseconds to femtoseconds. ${ }^{15-27}$ In these experiments, the biological function of ligand detachment from the heme is triggered by an optical (so-called pump) pulse, while the evolution of the system is probed by a second (typically optical or $\mathrm{X}$-ray) pulse, with a tunable time delay with respect to the pump pulse. While optical tools can reach femtosecond resolution they do not provide direct structural information. To overcome this, time-resolved X-ray protein crystallography was implemented, and has now reached the 100 ps resolution, ${ }^{28,29}$ unraveling a detailed mapping of the photoinduced ligand detachment and recombination in carboxymyoglobin. ${ }^{30-32}$

Modern crystallographic techniques make it possible to determine the global structure of the protein with almost atomic resolution. ${ }^{33}$ However, ideally one would prefer to determine the structure of the protein in its physiologically relevant environment. In addition, the biological function and reactivity of $\mathrm{Mb}$ strongly depends on the electronic structure of the active site. The iron atom of the heme group may exist in three different oxidation states (ferrous, ferric and ferryl) and its valence $3 \mathrm{~d}$ electrons are significantly delocalised into the porphyrin and ligand $\pi^{*}$ orbitals. In fact, the ability of the heme to redistribute the charge and spin density of the iron plays an important role in the formation and stabilization of a variety of intermediates important for biological function. ${ }^{34,35}$

For determining both the local geometric and the electronic structure around the active center (Fig. 1), X-ray absorption spectroscopy (XAS) is an important tool. ${ }^{36-38}$ Soft X-ray spectroscopy at the $\mathrm{L}_{2 / 3}$-edges ${ }^{39-42}$ can, by virtue of the dipole selection rules, directly probe the iron $3 \mathrm{~d}$ orbitals which are not observable in optical spectroscopy owing to the strong $\pi \rightarrow \pi^{*}$ (Soret) band. However, the $\mathrm{L}_{2 / 3}$-edges of iron are less sensitive to the geometric structure than the K-edge, for which bond length, angles and dihedrals may be extracted by the analysis of the spectral resonances occurring above the ionization potential in both the X-ray absorption near edge structure (XANES) and the extended X-ray absorption fine structure (EXAFS) regions, while the electronic structure is obtained via the pre-edge region of the spectrum. These attributes have led several groups to implement XAS for the study of heme proteins. ${ }^{39,43-51}$

Despite the fact that the physiological environment is the most relevant to the biological function, XAS studies of heme proteins under physiological conditions $(\mathrm{pH} 7$ solution, room temperature and pressure) are almost completely lacking, except for the recent soft X-ray studies carried out at the Fe $\mathrm{L}_{2 / 3}$-edges. ${ }^{40,42,52}$ Low temperature frozen solutions of heme proteins have generally been used as they reduce the thermal vibration of the atoms and, in the case of photolysed samples, trap intermediates so that their structures could be determined. However, aside from being far from the conditions in which proteins function, these samples are prone to radiation damage and lysis. ${ }^{49,53}$ It is therefore useful to investigate the photoinduced ligand detachment and recombination of heme proteins in physiological solutions which can be flowed continuously to ensure the renewal of the sample and decrease the X-ray dose deposited in each molecule. Recently, the first demonstration of time-resolved X-ray scattering ${ }^{54,55}$ and XAS ${ }^{27,56}$ with 100 ps resolution of MbCO in solutions was reported. The latter studies open the possibility for the study of the structural dynamics of photoexcited heme proteins using time-resolved XAS. However, prior to this it is essential to obtain and understand the XAS spectra of the ground state protein in solution.

Here we report a systematic Fe K-edge XAS investigation of ferric and ferrous myoglobins in physiological solutions. By studying a wide selection of myoglobins, using the same experimental and theoretical approaches we provide a consistent structural refinement around the heme. The ferric species are: aquomet myoglobin (metMb) and cyanomyoglobin (MbCN). The ferrous ones are: the deligated myoglobin (deoxyMb) and the ligated species oxymyoglobin $\left(\mathrm{MbO}_{2}\right)$, nitrosylmyoglobin ( $\mathrm{MbNO}$ ) and carboxymyoglobin (MbCO). The structural analysis, based on multiple scattering (MS) theory, implemented within the MXAN package ${ }^{57-60}$ is able to account for the spectral differences as a function of ligand substitution (see Fig. 1 and Section S2.1, ESI, $\dagger$ for a description of the structural parameters that were optimised in this work). We demonstrate that, contrary to the range of values obtained from crystallographic refinements, the average iron-nitrogen 
bond lengths in the porphyrin ring converge to a common value of about $2 \AA$ over the whole series of Mbs, apart from the special case of deoxyMb. Although many of the remaining structural parameters, i.e. the distance between the iron atom and the closest atom of the ligand, the tilt angle of the ligand and the $\mathrm{Fe}-\mathrm{N}_{\varepsilon}$ (proximal histidine) distance, are found to be similar to those reported from crystallographic analysis, differences do occur that reveal structural trends between the different ligands. In addition, the present analysis enables us to quantify the magnitude of the heme doming in the unligated form (deoxyMb). Finally, the electronic structure is investigated using the pre-edge structures, analysed with time-dependent density functional theory (TD-DFT), ${ }^{61,62}$ implemented within the ORCA quantum chemistry package. ${ }^{63,64}$ We find that these features are predominantly $1 \mathrm{~s} \rightarrow \mathrm{d}_{\sigma}$ and $1 \mathrm{~s} \rightarrow \mathrm{d}_{\pi}-\pi_{\text {ligand }}{ }^{*}$ transitions, while $1 \mathrm{~s} \rightarrow \mathrm{d}_{\pi}$ transitions also weakly contribute for $\mathrm{MbO}_{2}$, metMb and deoxyMb. Despite the dominant Fe d contribution to the valence molecular orbitals, these transitions draw their intensity from the dipole (4p) transition moment due to the low symmetry of the heme environment.

The experimental procedure for static XAS experiments has already been described in ref. 65-67 and is presented in the ESI. $\dagger$ Briefly, the Mb XAS spectra were collected at the microXAS beamline at the Swiss Light Source (Paul Scherrer Institut). The $\mathrm{X}$-rays were monochromatized using a double-crystal, fixed exit monochromator (DCM) using a Si(111) crystal pair yielding an energy resolution of $\sim 1 \mathrm{eV}$. The X-ray energy was calibrated with an iron foil, setting the energy of the first derivative of the XAS spectrum to $7112 \mathrm{eV}$. The spectra were acquired in total fluorescence yield mode using two single-element silicon drift detectors (Ketek, AXAS-SDD10-138500, $10 \mathrm{~mm}^{2}$ active area). We used lyophilized powder $\mathrm{Mb}$ from equine skeletal muscle (Sigma-Aldrich), with a purity $95-100 \%$, dissolved in a sodium phosphate buffer at $\mathrm{pH} 7.0$ and a concentration of $4 \mathrm{mM}$. The UV-Vis absorption spectra of the solutions were monitored throughout the experiment and were found to be consistent with the literature (see Fig. S2, ESI $\dagger$ ). The MbCN was prepared in basic solution to prevent the formation of $\mathrm{CN}$ gas, as described in the ESI. $\dagger$ The $\mathrm{pH}$ was not corrected afterwards and therefore is the only case that slightly deviates from physiological conditions. Nevertheless, this approach is preferable to soaking a metMb crystal in a $\mathrm{CN}$-containing solution in which binding is uncontrolled, and is the standard way of making crystals of ligated $\mathrm{Mb}$. In fact, for MbNO just soaking the crystal in NO-containing solution yields a different crystal structure. Further details of the preparation protocol of the Mbs, the structural parameters used to describe the heme environment, the procedure for the fits of the spectra and the computational details for the TD-DFT simulations are described in the ESI. $\dagger$

\section{Results}

The iron K-edge XAS spectra of six myoglobin types, at room temperature and a concentration of $4 \mathrm{mM}$, are shown in Fig. 2a. Each of the spectra exhibits several prominent features, labelled A to E, which are magnified in Fig. $2 \mathrm{~b}-\mathrm{d}$. For the above ionisation resonances (B-E), the variations point to differences

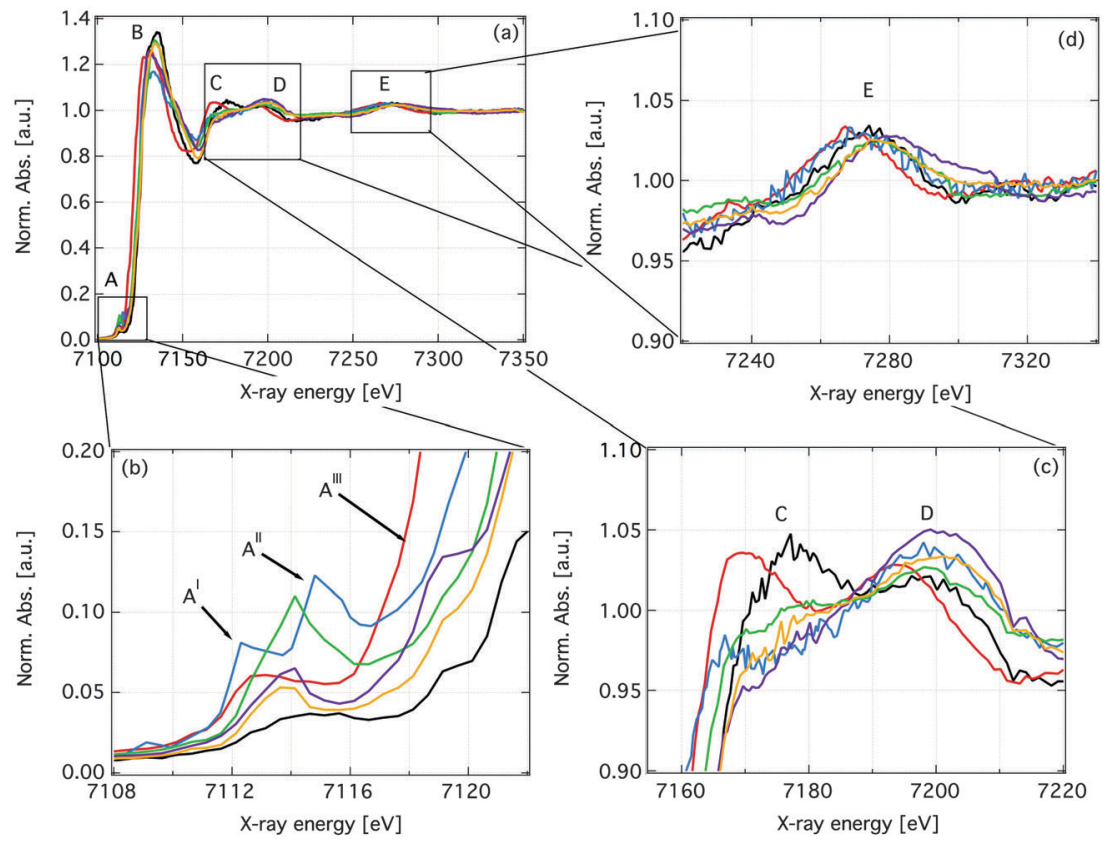

Fig. 2 (a) Steady-state XAS spectra of the different forms of myoglobin in solution. Blue $=M b C O$, green $=M b N O$, yellow $=M b O_{2}$, purple $=M b C N$, black = metMb and red $=$ deoxyMb. The main spectral features are labelled A-E. (b) Zoom of the pre-edge region of the XAS spectra of the different forms of myoglobin in solution. Note the presence of multiple features and the clear differences between the myoglobin forms. Feature $\mathrm{A}^{\prime}$ is present in all spectra and $A^{l l}$ is only present in $\mathrm{MbCO}$. $\mathrm{A}^{\mathrm{lll}}$, which is on the rising edge, is most pronounced in MbCN. (c) Zoom of the MS resonances $\mathrm{C}$ and $\mathrm{D}$. (d) Zoom of the single scattering resonance, $\mathrm{E}$. 
in the heme structure upon substitution of a ligand by another. The features B to D have previously been assigned to multiplescattering XANES resonances, ${ }^{48,68}$ feature $E$ is in the energy range normally considered part of the EXAFS region and is dominated by single-scattering contributions of the first coordination shell around iron. To our knowledge, feature $\mathrm{C}$ has not been assigned, but it is clearly more pronounced in metMb and deoxyMb.

Besides the variations above the edge, we also observe differences in the pre-edge region (Fig. 2b). The features therein correspond to bound-bound transitions into the unoccupied valence orbitals below the ionisation potential and they therefore bear information about the electronic structure. All the spectra, except MbCO, exhibit two resonances, centred around $7.114 \mathrm{keV}$ and $7.119 \mathrm{keV}$, which are interpreted below.

It is interesting to note that the edge positions $\left(E_{0}\right)$ of all of the spectra (corresponding to the ionization potential), defined as the maximum of the first derivative of the edge region, exhibit no distinct trend across the various forms of $\mathrm{Mb}$ (see Table S1, ESI $\dagger$ ), indicating that using $E_{0}$ to determine the oxidation state of the iron is not accurate and that the electronic structure of the iron atom is strongly influenced by the chemical nature of the ligands. Hocking et $a l .{ }^{69}$ reported that for ferric complexes, the porphyrin acts as a strong $\pi$-donor, while in the ferrous case it becomes a weak $\pi$-acceptor and can therefore be expected to somewhat compensate the oxidation state change of the metal. This points to the strong delocalisation of the iron $3 \mathrm{~d}$ electrons into the porphyrin and ligand $\pi^{*}$ orbitals, which plays an essential role in the formation and stabilization of a variety of intermediates important for biological function. ${ }^{34,35}$ Besides the heme, the chemical bonding of the ligand will also modulate the charge transfer from the iron atom through the mechanism of $\pi$-backbonding and $\sigma$-donation and consequently the edge shift, being a combination of these effects, will be difficult to relate only to the oxidation state of the iron.

\section{Analysis}

In the following, we present our analysis of both the geometric and electronic structure for each form of myoglobin. The computational details and structural parameters used to describe the heme environment and the fitting procedure for spectra are described in the ESI. $\dagger$

\subsection{MbCO}

The structure and dynamics of MbCO have been widely studied, with much effort aimed at understanding the difference between the affinity of $\mathrm{CO}$ ligation with respect to $\mathrm{O}_{2} \cdot{ }^{9}$ The strong IR absorption of the CO bond ${ }^{70-72}$ in conjunction with the high photolysis yield under physiological conditions has led to numerous time-resolved IR investigations. ${ }^{12,17,73-76}$ Besides IR spectroscopy, MbCO and its photolysed counterpart have been studied using X-ray spectroscopic ${ }^{25,68,77,78}$ and diffraction techniques. ${ }^{30,31,79-83}$ Della-Longa et $a .^{47}$ and Arcovito et al. ${ }^{51}$ performed iron K-edge polarized XANES investigations of $\mathrm{MbCO}$ at 20 and $100 \mathrm{~K}$ respectively. Their results largely agree with other previous studies (see Table 1 ) and only a slight increase in the $\mathrm{Fe}-\mathrm{C}$ and $\mathrm{C}-\mathrm{O}$ distances were reported. In both cases, $\alpha$, the angle between the direction perpendicular to the heme plane and the vector defined by the bond between the Fe and $\mathrm{C}_{\mathrm{CO}}$ (see Fig. S1, ESI $\dagger$ ), was not reported due to the low sensitivity of the fit to this parameter. This angle is thought to be important for the mechanism through which Mb suppresses the binding of $\mathrm{CO}$ compared to $\mathrm{O}_{2}{ }^{84,85}$ and it has only been assigned using XRD (see Table S1, ESI $\dagger$ ). ${ }^{33,86}$

Table 1 Summary of literature results for $\mathrm{MbCO}$

\begin{tabular}{|c|c|c|c|c|c|c|c|}
\hline & This work & Ref. 86 & Ref. $33^{a, c}$ & Ref. $87^{d}$ & Ref. 47 & Ref. 88 & Ref. $51^{g}$ \\
\hline $\mathrm{Fe}-\mathrm{N}_{\mathrm{p}}[\AA]$ & $2.01 \pm 0.01$ & 2.005 & $1.98 \pm 0.02$ & 1.97 & $2.00 \pm 0.02$ & $2.01 \pm 0.02^{g}$ & $1.98 \pm 0.01$ \\
\hline $\operatorname{Disp}[\AA]$ & -0.05 & +0.015 & $-0.048 \pm 0.005$ & - & - & - & - \\
\hline Dom1 [A] & - & - & -0.047 & - & - & - & - \\
\hline $\operatorname{Dom} 2[\AA]$ & - & - & - & - & - & - & - \\
\hline $\mathrm{Fe}-\mathrm{Li}[\AA]$ & $1.83 \pm 0.01$ & $1.73 \pm 0.03$ & $1.82 \pm 0.02$ & 1.92 & $1.83 \pm 0.02$ & $1.80 \pm 0.06$ & $1.86 \pm 0.03$ \\
\hline$\alpha\left[{ }^{\circ}\right]$ & $22 \pm 10^{b}$ & $4.7 \pm 0.9$ & 9.0 & - & - & - & - \\
\hline$\beta\left[^{\circ}\right]$ & $5 \pm 5$ & $7.4 \pm 1.9$ & $9 \pm 3$ & $39 / 60$ & $14 \pm 4$ & - & $16 \pm 2$ \\
\hline $\mathrm{L}_{1}-\mathrm{L}_{2}[\AA]$ & $1.11 \pm 0.02$ & $1.12 \pm 0.03$ & $1.09 \pm 0.02$ & $1.17 / 1.20$ & 1.07 & - & $1.13 \pm 0.07$ \\
\hline Technique & XANES & XRD & XRD & XRD & XANES & EXAFS & XANES \\
\hline Mb source & Horse muscle & Sperm whale & Sperm whale & Sperm whale & Sperm whale & Sperm whale & Sperm whale \\
\hline Temp. [K] & 298 & 287 & 100 & 260 & 20 & 20 & 100 \\
\hline PDB entry & - & 1BZR & 1A6G & $1 \mathrm{MBC}$ & - & - & - \\
\hline
\end{tabular}

${ }^{a}$ Input PDB structure for MXAN optimization. ${ }^{b}$ The spectrum is only weakly dependent on the angle $\alpha$ and most of the square residual derives from the rising edge region of the spectrum, which is the most troublesome for theoretical analysis. See the main text for a detailed discussion on this issue. ${ }^{c}$ Though only a single CO geometry was obtained from this result, two distal histidine (Hist64) geometries with respect to the CO were obtained. ${ }^{d}$ This result required two CO geometries to fit the data. ${ }^{e}$ This corresponds to the angle between the CO bond and the normal to the heme plane and is convenient for comparison to IR spectroscopy. ${ }^{f}$ This EXAFS result was unable to distinguish between the porphyrin and proximal histidine $\mathrm{N}$ atoms. ${ }^{g}$ Values reported are averages from two approaches for calculation of the muffin-tin potential, see ref. 51 for details. 

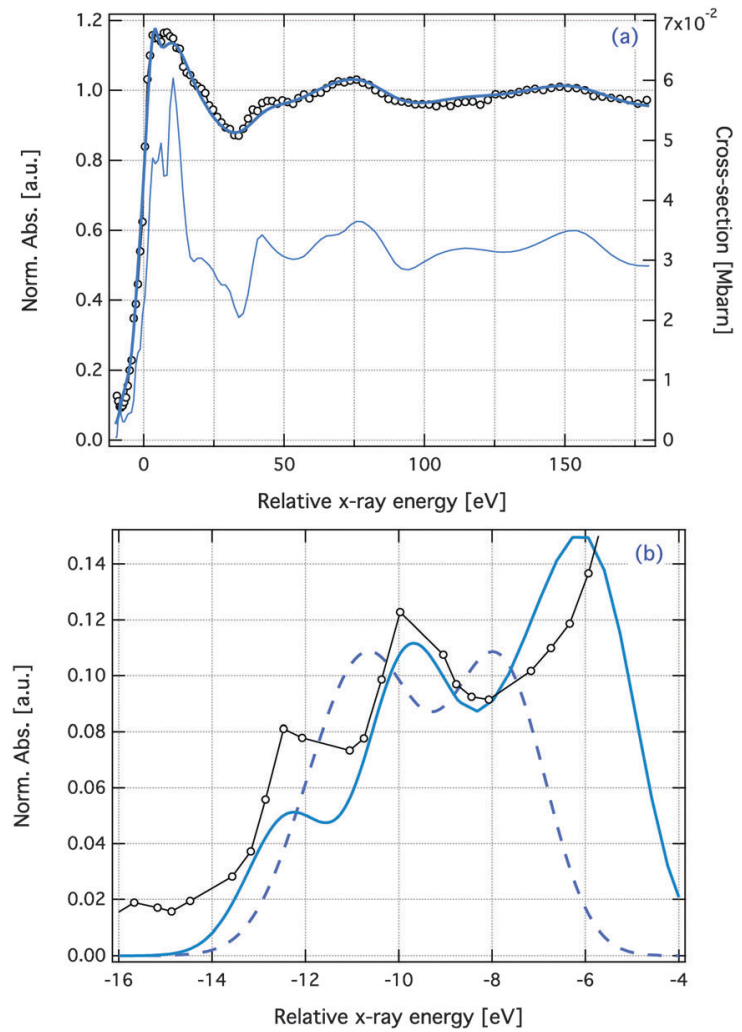

Fig. 3 MXAN best fit of the XAS spectrum of MbCO (a) and the preedge spectrum calculated using TD-DFT within the approximation of the BP86 (dashed) and B3LYP (solid) functionals broadened with a Lorentzian width of $2.0 \mathrm{eV}$ (b). The energy scale used in the fits is relative to the position of the first derivative of the XAS spectra, which is a first guess of the $E_{0}-$ see Table $S 1(E S I \dagger)$. Details of the calculation are given in the ESI. $\dagger$ The experimental data are represented by open circles. In (a) the calculated total cross-section, i.e. unconvoluted with respect to the lifetime broadening function, is represented by the thin solid line (right axis).

Our XANES analysis of MbCO is shown in Fig. 3a and the summary of the structural parameters, obtained from the minimisation of the square residual between the experiment and theory, is reported in Table 1. Notably, this yields $\alpha=22 \pm$ $10^{\circ}$, significantly larger than the values previously determined from the crystallographic structure and polarised IR spectroscopy, which gives the angle between the CO bond and the normal to the heme plane (corresponding to those shown in Table 1) to be $\leq 7 .{ }^{73}$ However, the large error associated with this value points to a weak sensitivity of the spectrum to this parameter and this is confirmed in Fig. S3 (ESI $\dagger$ ) showing the variation of the calculated spectrum as a function of $\alpha$. Although the overall square residual points to a best fit value of $22^{\circ}$, the agreement above the rising edge $(E \geq 5 \mathrm{eV})$ is clearly improved for smaller values of $\alpha$. In fact, Fig. S3e (ESI $\dagger$ ) shows that the majority of this square residual derives from the rising edge and changes in the post-edge which contribute little to the total square residual are reduced for smaller angles of $\alpha$, in agreement with the previous studies shown in Table 1. From this we conclude that our spectrum is sensitive to $\alpha$, however the changes are subtle meaning that a combination of higher quality data and an accurate theoretical treatment of many body effects, which are important close to the edge, is required to be able to assign $\alpha$ with certainty.

Insight into the electronic structure of the heme, following the structural refinement, can be assessed by simulation of the pre-edge region. Fig. 3b shows experimental and calculated spectra using the B3LYP* ${ }^{89-91}$ containing $15 \%$ Hartree-Fock exchange (HFX), ${ }^{92,93}$ and BP86 exchange and correlation $(x-c)^{94}$ functionals. The former was chosen because, for weak field complexes, it yields a better description of the d-orbitals splitting than $\mathrm{B}^{2} \mathrm{LYP}^{92}$ and its effect on Fe K-edge spectra was recently demonstrated for $\left[\mathrm{Fe}(\mathrm{bpy})_{3}\right]^{+93}$ for which B3LYP gave $1 \mathrm{~s} \rightarrow 3 \mathrm{~d}\left(e_{\mathrm{g}}\right)$ transitions which were too low relative to other transitions.

The BP86 functional (dashed line) yields one feature below $-9 \mathrm{eV}$, consisting of two principal resonances separated by $1 \mathrm{eV}$ (less than the $2 \mathrm{eV}$ broadening), having $1 \mathrm{~s} \rightarrow \mathrm{d}_{\sigma}$ and $1 \mathrm{~s} \rightarrow$ $\mathrm{d}_{\pi}-\pi_{\mathrm{CO}}{ }^{*}$ characters, respectively. However, this resonance does not agree with the experimental spectrum, which contains a clear doublet structure. In contrast, the B3LYP* functional replicates the doublet observed experimentally both here and in ref. 95. In this latter case, the two resonances have the same character as those described above, but the inclusion of HFX increases the separation of the states. The lower transition, $1 \mathrm{~s} \rightarrow \mathrm{d}_{\sigma}$, decreases in energy due to the limitation of generalized gradient approximation (GGA) functionals (BP86) to correctly predict the splitting of the d-orbital in weak field transition metal complexes. ${ }^{92}$ The higher, $1 \mathrm{~s} \rightarrow \mathrm{d}_{\pi}-\pi_{\mathrm{CO}}{ }^{*}$, transition increases in energy owing to the improved description of the $\pi$-backbonding required to represent $\mathrm{Fe}-\mathrm{CO}$ bonds. ${ }^{85,96}$ Despite the large Fe d contribution to the molecular orbitals involved in these transitions, the low symmetry around the iron, i.e. loss of centrosymmetric symmetry, implies $3 \mathrm{~d} / 4 \mathrm{p}$ mixing and these transitions are in fact dominated by the dipole component arising from the small amount of $4 \mathrm{p}$ character. This is in agreement with ref. 97 on low symmetry iron complexes and is evidenced in both experiment and theory by the relative heights between the two peaks. If the quadrupole moment were the principal component, the lower energy peak $\left(\mathrm{A}^{\prime}\right)$, which consists of a $1 \mathrm{~s} \rightarrow \mathrm{d}_{\sigma}$ transition, would be more intense than the higher peak which is of $1 \mathrm{~s} \rightarrow \mathrm{d}_{\pi}-\pi_{\mathrm{CO}}{ }^{*}$ character.

Finally, the feature at $-6 \mathrm{eV}$ in the calculated spectrum corresponds to a $1 \mathrm{~s} \rightarrow 4 \mathrm{p}$ transition. Its proximity to the edge means that the final state wavefunction of this transition is rather diffuse and would require the inclusion of a larger number of residues beyond the heme and proximal hisitidine to yield a quantitative description. As shown later, its appearance in the experimental spectrum is a sensitive probe of the edge position, but also the distribution of $4 \mathrm{p}$ character throughout the valence space. We therefore use this transition in a qualitative manner throughout the remaining forms of myoglobin. Here, the low ionisation potential $\left(E^{0}\right.$, see Table S1, ESI $\dagger$ ) means that this transition is beneath the rising edge associated with the continuum and is not observed in the experimental spectrum. 


\subsection{MbNO}

Besides its role for the storage and diffusion of oxygen, recent investigations have implicated $\mathrm{Mb}$ as a nitric oxide (NO) scavenger in heart and skeletal muscle. ${ }^{6} \mathrm{~A}$ wide variety of functions have also been reported in other heme proteins, such as hemoglobin and nitrophorin. Therefore the reactivity and function of NO is thought to be closely related to its electronic and geometric structure upon binding. ${ }^{98}$ Zemojtel et al. ${ }^{99}$ have recently postulated, using femtosecond infrared polarization spectroscopy, that the electrostatic energy within the heme pocket has a significant bearing on the structure of the Fe-NO, leading to a specific NO recognition strategy for heme proteins.

In contrast to $\mathrm{MbCO}$, the structural refinements of $\mathrm{MbNO}$ appear to reflect larger variations depending on the conditions and specifically, the temperature (see Table 2 for a list of structural parameters from the literature). Using EXAFS analysis on cryo-cooled samples, ${ }^{88,100} \mathrm{Fe}-\mathrm{N}_{\varepsilon}$ distances to the proximal histidine of 2.05 and $2.08 \AA$ were obtained, while in contrast, analysis of the XRD of room temperature samples found $2.18 \AA$, in close agreement with the $\mathrm{Fe}-\mathrm{N}_{\varepsilon}$ distance at $100 \mathrm{~K}$ extracted from a polarized XANES analysis. ${ }^{51}$ Besides this, there are also significant differences for the bending angle $\beta$ (Fig. S1, ESI $\dagger$ ). The linearity of the $\mathrm{Fe}-\mathrm{N}-\mathrm{O}$ angle is broken owing to the extra antibonding electron, compared to $\mathrm{CO}$. This electron causes an antibonding interaction between the $\mathrm{d}_{\sigma}$ and $\pi_{\mathrm{NO}}{ }^{*}$ orbitals and the bending minimises it. This reduces the $\pi$-back-bonding interaction, which although is somewhat compensated for by enhanced back-bonding perpendicular to the bending plane, is still expected to result in a weaker Fe-NO bond. ${ }^{101}$

Variations in the bending angle have also been reported to be dependent on the preparation method ${ }^{102-104}$ and in particular, the NO geometry relative to the iron atom varies considerably depending on whether MbNO is prepared in solution or in crystalline form ${ }^{100}$ and whether the crystals are prepared from the reaction of metMb with nitrite/dithionite or directly from the reaction of NO gas with deoxyMb. It has been speculated that these differences arise from interactions with the distal pocket, which stabilises local Fe-NO conformational minima. ${ }^{103}$ Specifically, when the sample is crystallized as metMb and subsequently reduced (NO gas method), the distal pocket and the distal histidine force a strained binding geometry on the NO. ${ }^{100}$

From our present analysis, derived from MbNO synthesised using $\mathrm{NaNO}_{2}$, we find an $\mathrm{Fe}-\mathrm{N}-\mathrm{O}(\beta)$ angle of $35 \pm 1^{\circ}$, in agreement with the analysis of Copeland et al. ${ }^{102,103}$ using the same preparation method and the low temperature study in ref. 51. Regarding the angle $\alpha$, our value of $13 \pm 6^{\circ}$ agrees with the few available reports. ${ }^{102,103}$ In agreement with ref. 104, the $\mathrm{Fe}-\mathrm{N}_{\varepsilon}$ bond length is larger than $\mathrm{MbCO}$ and $\mathrm{MbO}_{2}$ and is due to the large repulsive trans effect of NO heme complexes. ${ }^{105}$ Recent QM/MM simulations ${ }^{106}$ reported that this bond length is also sensitive to the protonation state of the His93, as the nearby Serine 92, which offers a hydrogen bond, can affect its geometry. ${ }^{107}$ Given that the $\mathrm{p} K_{\mathrm{a}}$ of histidine is 6.5 , it is likely that deviations from physiological conditions will have an important bearing on the protonation and consequently on this bond length, meaning that the present structure, in agreement with that of ref. 104 is the most relevant for the protein in its natural environment.

The pre-edge region of MbNO (Fig. 4b), in contrast to that of MbCO, exhibits only one feature at $-11 \mathrm{eV}$. Likewise, it is dominated by transitions of $1 \mathrm{~s} \rightarrow \mathrm{d}_{\sigma}$ and $1 \mathrm{~s} \rightarrow \mathrm{d}_{\pi}-\pi_{\mathrm{NO}}{ }^{*}$ character. However, because $\pi$-backbonding is smaller for $\mathrm{Fe}-\mathrm{N}-\mathrm{O}$, their separation is less than our experimental resolution and therefore they appear as one feature. In this case, the simplified bonding means that the BP86 functional achieves good agreement with the experimental spectrum, as is usually encountered for iron K-edges ${ }^{62}$ and therefore we use only this functional throughout the remainder of the work. The feature at $-6 \mathrm{eV}$, like $\mathrm{MbCO}$, corresponds to the $1 \mathrm{~s} \rightarrow 4 \mathrm{p}$ transition and in this case there appears to be a weak transition corresponding to it in the experimental spectrum. This is to be expected for

Table 2 Summary of literature results for $\mathrm{MbNO}$

\begin{tabular}{|c|c|c|c|c|c|c|c|c|}
\hline & This work & Ref. 104 & Ref. 88 & Ref. $103^{a}$ & Ref. 103 & Ref. 102 & Ref. 100 & Ref. $51^{c}$ \\
\hline $\mathrm{Fe}-\mathrm{N}_{\mathrm{p}}[\AA]$ & $2.009 \pm 0.008$ & 2.08 & $2.02 \pm 0.02^{b}$ & 2.05 & 2.07 & 2.00 & $2.00 \pm 0.02$ & $2.01 \pm 0.03$ \\
\hline $\operatorname{Disp}[\AA]$ & -0.04 & $0.00 \pm 0.01$ & - & - & -0.13 & 0.00 & - & - \\
\hline Dom1 $[\AA]$ & - & - & - & - & - & - & - & - \\
\hline $\operatorname{Dom} 2[\AA]$ & - & - & - & - & - & - & - & - \\
\hline $\mathrm{Fe}-\mathrm{Li}[\AA ⿻ \circ$ & $1.82 \pm 0.02$ & $1.89 \pm 0.04$ & $1.76 \pm 0.06$ & 1.87 & 2.13 & 2.03 & $1.75 \pm 0.02$ & $1.93 \pm 0.02$ \\
\hline$\alpha\left[{ }^{\circ}\right]$ & $13 \pm 6$ & - & - & 9 & 9 & - & - & - \\
\hline$\beta\left[^{\circ}\right]$ & $35 \pm 1$ & $68 \pm 5$ & - & 36 & 60 & 33 & $30 \pm 2$ & $61 \pm 27$ \\
\hline $\mathrm{Fe}-\mathrm{N}_{\varepsilon}[\AA]$ & $2.15 \pm 0.03$ & $2.18 \pm 0.03$ & $2.02 \pm 0.02^{b}$ & 2.08 & 2.14 & 2.11 & $2.05 \pm 0.03$ & $2.13 \pm 0.03$ \\
\hline $\mathrm{L}_{1}-\mathrm{L}_{2}[\AA]$ & $1.23 \pm 0.03$ & 1.15 & - & 1.20 & 1.17 & 1.14 & $1.12 \pm 0.02$ & $1.13 \pm 0.04$ \\
\hline Technique & XANES & XRD & EXAFS & XRD & XRD & XRD & XANES & XANES \\
\hline Mb source & Horse muscle & Sperm whale & Sperm whale & Horse heart & Horse heart & Horse heart & Horse heart & Sperm whale \\
\hline Temp. [K] & 298 & 295 & 30 & 100 & 100 & 100 & 10 & 100 \\
\hline Prep & $\mathrm{NaNO}_{2}$ & NO gas & $\mathrm{NaNO}_{2}$ & $\mathrm{NaNO}_{2}$ & NO gas & $\mathrm{NaNO}_{2}$ & NO gas & Unspecified \\
\hline PDB entry & - & $1 \mathrm{HJT}$ & - & $2 \mathrm{FRJ}$ & 2FRK & $1 \mathrm{NPF}$ & - & - \\
\hline Res. [̊] & - & 1.70 & - & 1.30 & 1.30 & 1.90 & - & - \\
\hline$R$-value & - & 0.162 & - & 0.180 & 0.170 & 0.199 & - & - \\
\hline
\end{tabular}

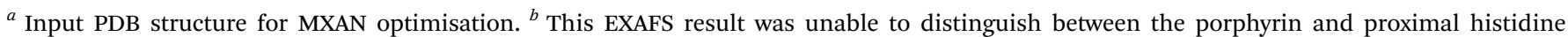
$\mathrm{N}$ atoms. ${ }^{c}$ Values reported are averages from two approaches for calculation of the muffin-tin potential, see ref. 51 for details. 

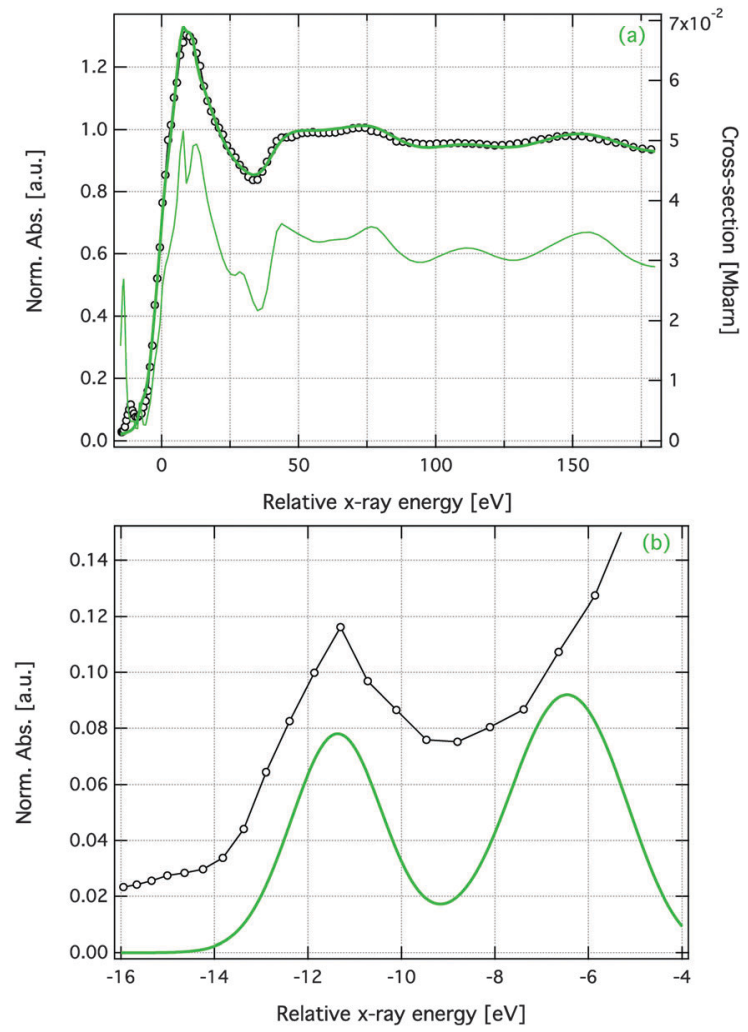

Fig. 4 MXAN best fit of the XAS spectrum of MbNO (a) and the pre-edge spectrum calculated using TD-DFT within the approximation of the BP86 functional (b). Details of the calculations are given in the ESI. $\dagger$ The experimental data are represented by open circles. In (a) the calculated total cross-section, i.e. unconvoluted with respect to the lifetime broadening function, is represented by the thin solid line (right axis). The energy scale used in the fits is relative to the position of the first derivative of the XAS spectra, which is a first guess of the $E_{0}$ - see Table S1 (ESI $\dagger$ ).

MbNO because $E_{0}$ is $\sim 0.3 \mathrm{eV}$ higher energy than for $\mathrm{MbCO}$ and therefore the $1 \mathrm{~s} \rightarrow 4 \mathrm{p}$ transition is slightly less concealed by the rising edge.

\section{$3.3 \quad \mathrm{MbO}_{2}$}

$\mathrm{MbO}_{2}$ is responsible for the transport and storage of oxygen in red blood cells and is the most biologically relevant form of myoglobin. However, somewhat surprisingly the highest resolution crystallography refinements suggest that contrary to all of the other ligated $\mathrm{Mb}$ the $\mathrm{Fe}$ atom does not lie in the heme plane but below it, similar to the deoxy form. ${ }^{33,108}$ Our present refinement is shown in Fig. 5 and the structural parameters from this and previous studies are summarised in Table 3. Our results do not validate the previously reported domed configuration $^{33,108}$ and the heme is found to be planar, just as for the other ligated forms. Besides this, we find an $\mathrm{Fe}-\mathrm{O}$ distance of $1.92 \pm 0.01$, which is $\sim 0.1 \AA$, larger than previous refinements. In order to clarify this fit, Fig. S6 (ESI $\dagger$ ) shows the spectrum and the corresponding square residual as a function of the $\mathrm{Fe}-\mathrm{O}$ bond distance. Here deviations are clearly observed and importantly the spectrum for $\mathrm{Fe}-\mathrm{O}=1.81 \AA$, as previously
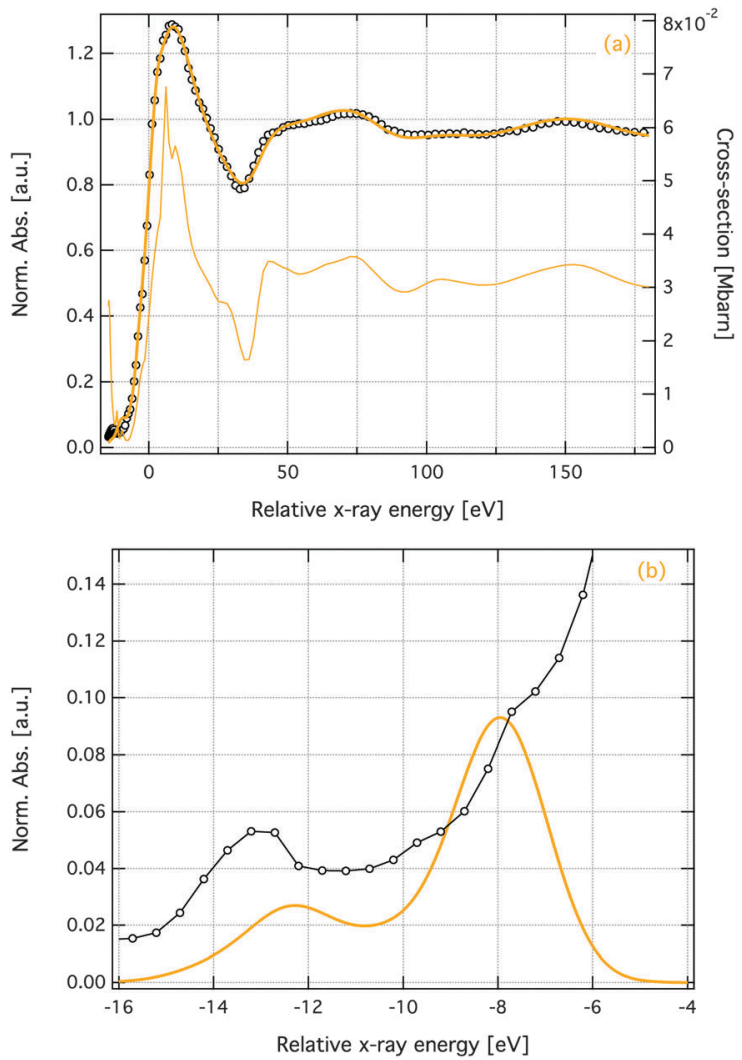

Fig. 5 MXAN best fit of the XAS spectrum of $\mathrm{MbO}_{2}$ (a) and the pre-edge spectrum calculated using TD-DFT within the approximation of the BP86 functional (b). Details of the calculations are given in the ESI. $\uparrow$ The experimental data are represented by open circles. In (a) the calculated total cross-section, i.e. unconvoluted with respect to the lifetime broadening function, is represented by the thin solid line (right axis). The energy scale used in the fits is relative to the position of the first derivative of the XAS spectra, which is a first guess of the $E_{0}$ - see Table S1 (ESI $\dagger$ ).

assigned $^{33,108-110}$ offers rather poor agreement with our experimental spectrum.

Although this is a large $(\sim 0.1 \AA)$ difference from previous refinements, it is consistent with the decrease in $\pi$-backbonding expected for $\mathrm{MbO}_{2}$ in comparison to MbCO. This causes a weakening (elongation) of the $\mathrm{Fe}-\mathrm{O}_{2}$ bond in comparison to $\mathrm{Fe}-\mathrm{CO}$ and $\mathrm{Fe}-\mathrm{NO}$ shown by our present results and not the refinement of ref. 33 for which the bond lengths are the same. In addition, the bound $\mathrm{O}_{2}$ is a good $\mathrm{H}$-bond acceptor, from the distal histidine which has been observed in both neutron diffraction ${ }^{111}$ and $\mathrm{NMR}^{112}$ investigations, likely contributing a further distortion.

The remaining structural parameters largely converge to those of the other ligated forms of myoglobin and previous refinements of $\mathrm{MbO}_{2}$. In particular, we find an $\mathrm{Fe}-\mathrm{N}_{\varepsilon}$ distance of $2.10 \pm 0.01$ which lies between the MbCO and MbNO values and is consistent with the expected trans ligand effect, which as stated previously is largest for NO. ${ }^{101}$ The angles $\alpha$ and $\beta$ are in good agreement with the structures summarised in Table 3, and it is interesting to note the large $\beta$, which is $50^{\circ} \pm 4$. This bending is consistent with increasing occupation of the 
Table 3 Summary of literature results for the structure of $\mathrm{MbO}_{2}$

\begin{tabular}{|c|c|c|c|c|c|c|}
\hline & This work & Ref. $108^{a}$ & Ref. 33 & Ref. 109 & Ref. 110 & Ref. 88 \\
\hline $\operatorname{Disp}[\AA]$ & $-0.04 \pm 0.03$ & -0.19 & $-0.089 \pm 0.003$ & - & - & - \\
\hline $\mathrm{Fe}-\mathrm{Li}\left[\AA{ }^{\circ}\right]$ & $1.92 \pm 0.01$ & 1.83 & $1.81 \pm 0.01$ & $1.80 \pm 0.02$ & 1.83 & $1.77 \pm 0.06$ \\
\hline$\alpha\left[^{\circ}\right]$ & $3 \pm 2$ & 4 & 0.3 & - & - & - \\
\hline$\beta\left[^{\circ}\right]$ & $50 \pm 4$ & 64 & $58 \pm 1$ & $57 \pm 4^{b}$ & 56 & - \\
\hline Technique & XANES & XRD & XRD & EXAFS & XRD & EXAFS \\
\hline Mb source & Horse muscle & Sperm whale & Sperm whale & Unknown & Sperm whale & Sperm whale \\
\hline Temp. [K] & 298 & 261 & 100 & 4 & 100 & 20 \\
\hline PDB entry & - & $1 \mathrm{MBO}$ & $1 \mathrm{~A} 6 \mathrm{M}$ & - & $2 \mathrm{Z6S}$ & - \\
\hline Res. [@] & - & 1.60 & 1.00 & - & 1.25 & - \\
\hline$R$-value & - & - & 0.122 & - & 0.187 & - \\
\hline
\end{tabular}

${ }^{a}$ Input PDB structure for MXAN optimization. ${ }^{b}$ A second geometry was also considered with $\beta=57 \pm 8^{\circ}$. ${ }^{c}$ This EXAFS result could not distinguish between the porphyrin and proximal histidine $\mathrm{N}$ atoms.

$\pi^{*}$ ligand orbitals, and as previously discussed for MbNO serves to reduce the antibonding interaction with the $\mathrm{d}_{\sigma}$. In addition, for $\mathrm{MbO}_{2}$ it is also expected that the hydrogen bonding of the oxygen atoms with the His64 induces a further bending into the structure. ${ }^{11}$

Besides geometric considerations there has been a significant effort aimed at understanding the bonding and electronic structure of $\mathrm{Fe}-\mathrm{O}_{2}$ in $\mathrm{MbO}_{2} \cdot{ }^{35,39,113-116}$ Fig. 5b shows the experimental and calculated pre-edge spectrum for $\mathrm{MbO}_{2}$, which exhibits a clear pre-edge feature at $-13 \mathrm{eV}$. The intensity of this feature, which also has a $1 \mathrm{~s} \rightarrow \mathrm{d}_{\sigma}$ and $1 \mathrm{~s} \rightarrow \mathrm{d}_{\pi}-\pi_{\mathrm{O}_{2}}{ }^{*}$ character, is significantly weaker than in $\mathrm{MbNO}$, pointing to a reduction in the $\mathrm{Fe} 3 \mathrm{~d}-4 \mathrm{p}$ mixing and a loss of the dipole component ( $1 \mathrm{~s} \rightarrow 4 \mathrm{p}$ ) contributing to these transitions. As the magnitude of $3 \mathrm{~d}-4 \mathrm{p}$ mixing is proportional to the $\mathrm{Fe}-\mathrm{X}$ bond length, ${ }^{97}$ this reduced $4 \mathrm{p}$ mixing points to a longer $\mathrm{Fe}-\mathrm{O}$ bond length, in comparison to MbCO and MbNO, consistent with the structural analysis (Table 3). In addition, it is important to notice the asymmetry of the pre-edge feature on the low energy side. This is due to a $1 \mathrm{~s} \rightarrow \mathrm{d}_{\pi}$ transition which suggests that in solution the electronic structure is best described by the Weiss model, ${ }^{114}$ i.e. $\mathrm{Fe}^{3+}-\mathrm{O}_{2}{ }^{-}$. Indeed a recent XAS study by Wilson et al. $^{117}$ came to the same conclusions for oxyhemoglobin, but also demonstrated that this asymmetry was absent in the crystal, highlighting the importance of performing such studies in physiological relevant media.

Finally, the $1 \mathrm{~s} \rightarrow 4 \mathrm{p}$ transition, which occurs at $\sim-8.5 \mathrm{eV}$, is clearly observed in the experiment and is in agreement with the calculation. In this case, in contrast to $\mathrm{MbNO}$ and $\mathrm{MbCO}$, $E_{0}$ occurs at higher energies, $(7126.8 \mathrm{eV}$, see Table S1, ESI $\dagger$ ) meaning that this transition is no longer concealed by the rising edge.

\subsection{MbCN}

$\mathrm{MbCN}$ is a ferric heme protein, formed by complexation of the cyanide anion $\left(\mathrm{CN}^{-}\right)$to the high-spin ferric heme of metMb, displacing the water ligand. MbCN, contrary to the previously

Table 4 Summary of literature results for $\mathrm{MbCN}$

\begin{tabular}{|c|c|c|c|c|c|c|}
\hline & This work & Ref. 51 & Ref. 50 & Ref. $50^{a, b}$ & Ref. $50^{c}$ & Ref. 121 \\
\hline $\mathrm{Fe}-\mathrm{N}_{\mathrm{p}}[\AA]$ & $1.99 \pm 0.04$ & $1.99 \pm 0.02$ & $2.01 \pm 0.03$ & 2.04 & 2.04 & 2.03 \\
\hline $\operatorname{Disp}[\AA]$ & 0.04 & - & - & - & - & In plane \\
\hline Dom1 [̊] & - & - & - & - & - & - \\
\hline $\operatorname{Dom} 2[\AA]$ & - & - & - & - & - & - \\
\hline $\mathrm{Fe}-\mathrm{Li}[\AA]$ & $1.92 \pm 0.04$ & $1.89 \pm 0.02$ & $1.87 \pm 0.04$ & 1.92 & 2.22 & 2.02 \\
\hline$\alpha\left[^{\circ}\right]$ & $11 \pm 5$ & - & - & - & - & 10 \\
\hline$\beta\left[^{\circ}\right]$ & $9 \pm 3$ & $7 \pm 4$ & $10 \pm 7$ & 13 & 14 & 14 \\
\hline $\mathrm{Fe}-\mathrm{N}_{\varepsilon}[\AA]$ & $2.06 \pm 0.01$ & $2.10 \pm 0.02$ & $2.07 \pm 0.03$ & 2.08 & 2.08 & 2.02 \\
\hline $\mathrm{L}_{1}-\mathrm{L}_{2}[\mathrm{~A}]$ & $1.1 \pm 0.03$ & $1.15 \pm 0.05$ & $1.10 \pm 2$ & 1.11 & 1.10 & 1.06 \\
\hline Technique & XANES & XANES & XANES & XRD & XRD & XRD \\
\hline Mb source & Horse muscle & Sperm whale & Sperm whale & Horse heart & Horse heart & Horse heart \\
\hline Temp. [K] & 298 & 100 & 100 & 100 & 100 & 300 \\
\hline PDB entry & - & - & - & $2 \mathrm{JHO}$ & $2 \mathrm{JHO}$ & $1 \mathrm{EBC}$ \\
\hline Res. $[\AA]$ & - & - & - & 1.40 & 1.40 & 1.8 \\
\hline$R$-value & - & - & - & 0.181 & 0.181 & 0.181 \\
\hline
\end{tabular}

${ }^{a}$ Input PDB structure for MXAN optimization. ${ }^{b}$ This diffraction result used XANES measurements of the active site to restrain the diffraction analysis. ${ }^{c}$ The same diffraction measurement as ${ }^{b}$ but unconstrained. 
discussed ligated forms of $\mathrm{Mb}$, is formed with a high affinity and has a very short photocycle $(<4 \mathrm{ps}){ }^{118,119}$ Previous structural refinements, summarised in Table 4 , have indicated that the bound $\mathrm{CN}$ ligand has a tilted geometry, while polarised Raman measurements have suggested that the hexacoordinate low-spin heme group is domed, ${ }^{120}$ however this has not been confirmed by either XAS or XRD.

Arcovito et $a l .{ }^{50}$ combined X-ray diffraction and polarized XANES to study the structure of MbCN. They showed that using the XANES derived parameters as constraints on the crystal structure refinement of the X-ray diffraction data, it was possible to achieve a higher precision for bond distances and bond angles around the iron (see Table 4). Later D'Angelo and co-workers ${ }^{46}$ used a combination of XANES and EXAFS analysis to investigate the heme environment of $\mathrm{MbCN}$, and obtained similar results to ref. 50. However the Fe-CN distance of $1.84 \pm 0.02 \AA$ obtained via EXAFS is underestimated, both compared to their own XANES analysis $(1.96 \pm 0.05 \AA)$ and to the polarized XANES results of Arcovito et $a l .{ }^{50}(1.87 \pm 0.04 \AA)$. This work also reports a rather large uncertainty in the $\mathrm{Fe}-\mathrm{C}-\mathrm{N}$ angle of $166^{\circ} \pm 20^{\circ}$, corresponding to $\beta \sim 14^{\circ} \pm 20^{\circ}$ in our structural parameters.

Our structural refinement of MbCN is shown in Fig. 6a, with the parameters given in Table 4 . Our results agree within the uncertainty with both the crystallographic ${ }^{33,86}$ and the structure derived from the XANES spectrum. ${ }^{50}$ In particular, the average $\mathrm{Fe}-\mathrm{N}_{\mathrm{p}}$ distance which converges to that of the other forms of $\mathrm{Mb}$. Both $\alpha, 11 \pm 5^{\circ}$ and $\beta, 9 \pm 3^{\circ}$, are in agreement with previous assignments and demonstrate a close similarity to the linear Fe-C-N moiety. ${ }^{122,123}$

Fig. $6 \mathrm{~b}$ shows a zoom of the experimental spectrum in the pre-edge region and the calculated spectrum. As discussed previously for $\mathrm{MbO}_{2}$, we observe one clear pre-edge feature owing principally to the $1 \mathrm{~s} \rightarrow \mathrm{d}_{\sigma}$ and $1 \mathrm{~s} \rightarrow \mathrm{d}_{\pi}-\pi_{\mathrm{CN}^{*}}$ transitions. Given the ferric oxidation state of $\mathrm{MbCN}$, as in the case of $\mathrm{MbO}_{2}$ previously, we observe an asymmetry on the low energy side of this pre-edge feature. This arises from $1 \mathrm{~s} \rightarrow \mathrm{d}_{\pi}$ transitions, but are weak because of the quadrupole character. The intensity of the first pre-edge feature is, like $\mathrm{MbO}_{2}$, weaker than in $\mathrm{MbCO}$ and $\mathrm{MbNO}$. Again, the longer Fe- $\mathrm{C}_{\mathrm{CN}}$ bond length reduces $3 \mathrm{~d}-4 \mathrm{p}$ mixing, and therefore this transition has a larger contribution from the quadrupole moments. Interestingly, the effect of the reduced $3 d-4 p$ mixing results in a clear transition at $\sim 5 \mathrm{eV}$ higher energy on the rising edge. This feature, common to the K-edge spectra of transition metal complexes, is a $1 \mathrm{~s}-4 \mathrm{p}$ (dipole-allowed) transition. As seen in the previous spectra, this is present in all of the calculated spectra, but it is only visible experimentally for the complexes with reduced $3 \mathrm{~d}-4 \mathrm{p}$ mixing at lower energy $\left(\mathrm{MbO}_{2}\right.$ and $\left.\mathrm{MbCN}\right)$.

\section{5 metMb}

In metMb, the ferric iron center is bound to a water molecule and has a high spin electronic configuration, which plays an important role in the reaction cycle with $\mathrm{MbNO}$ and $\mathrm{MbO}_{2}$. Oxymyoglobin can react rapidly (and irreversibly) with NO yielding nitrate and metMb, acting as an NO scavenger.
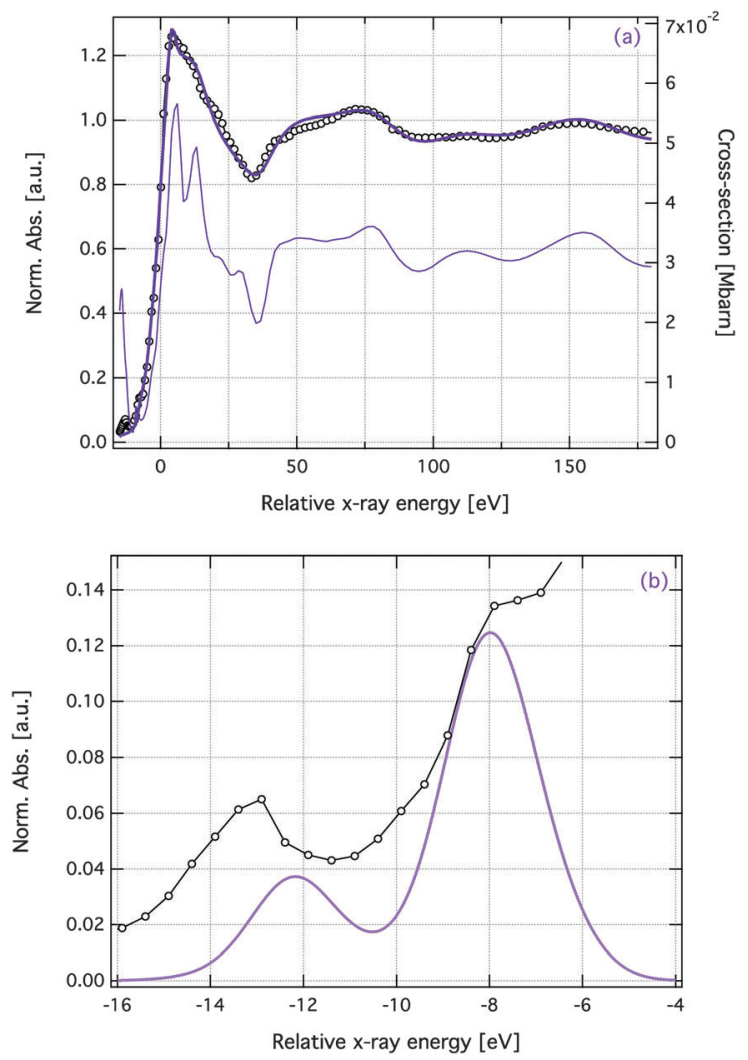

Fig. 6 MXAN best fit of the XAS spectrum of $\mathrm{MbCN}(\mathrm{a})$ and the pre-edge spectrum calculated using TD-DFT within the approximation of the BP86 functional (b). Details of the calculations are given in the ESI. $\dagger$ The experimental data are represented by open circles. In (a) the calculated total cross-section, i.e. unconvoluted with respect to the lifetime broadening function, is represented by the thin solid line (right axis). The energy scale used in the fits is relative to the position of the first derivative of the XAS spectra, which is a first guess of the $E_{0}-$ see Table S1 (ESI $\left.\dagger\right)$.

Here, metMb is reduced to form metMb-reductase, which can then bind to $\mathrm{NO}$ or $\mathrm{O}_{2}$, completing the cycle. ${ }^{6}$

Our fit of the XANES spectrum is given in Fig. 7a and the structural parameters are summarised in Table 5 . The fit, gives the best agreement with the experimental spectrum $\left(S^{2}=0.57\right)$ of all the series, and our results closely agree with the previous refinements, ${ }^{33,46,53,124,125}$ except for the Fe-Li distance which varies significantly from the results of studies given in Table 5 . To understand this, we calculated the spectrum without the oxygen atom in the position of the ligand, i.e., undistorted pentacoordinated geometry. The resulting spectrum (Fig. S7, $\mathrm{ESI} \dagger)$ has a larger square residue $\left(S^{2}=0.99\right)$, but overall the agreement is still good. This indicates that the bound oxygen has only a small effect on the spectrum and therefore cannot be expected as close to the iron as $\mathrm{CO}, \mathrm{NO}$ and $\mathrm{CN}$. However, importantly our present analysis of all forms of $\mathrm{Mb}$ demonstrate that the $\mathrm{C}$ feature is very sensitive to the presence of the ligand, and is significantly more pronounced in both deoxyMb and metMb. Given this sensitivity and the good agreement between experiment and theory we expect our present refinement to be more accurate than crystallographic structures. 

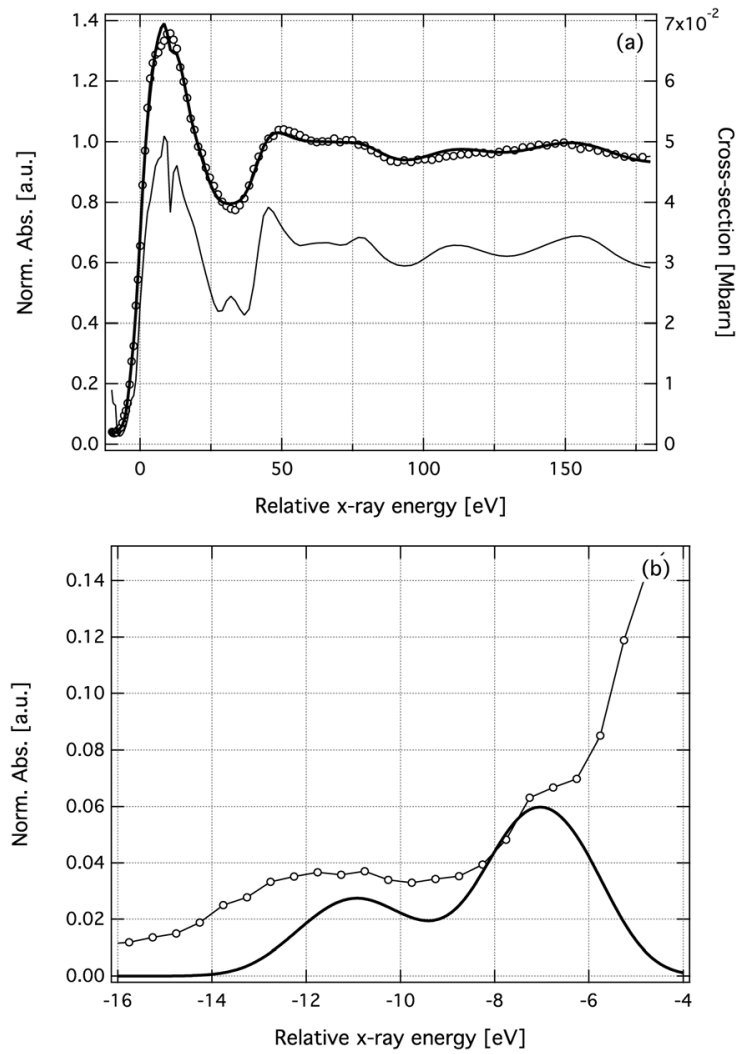

Fig. 7 MXAN best fit of the XAS spectrum of metMb (a) and the pre-edge spectrum calculated using TD-DFT within the approximation of the BP86 functional (b). Details of the calculations are given in the ESI. $\dagger$ The experimental data are represented by open circles. In (a) the calculated total cross-section, i.e. unconvoluted with respect to the lifetime broadening function, is represented by the thin solid line (right axis). The energy scale used in the fits is relative to the position of the first derivative of the XAS spectra, which is a first guess of the $E_{0}$ - see Table S1 (ESI $\dagger$ ).

Regarding the heme structure, the refinement in Table 5 includes only the displacement of the Fe from the heme plane (Disp), in contrast to the structure of ref. 33 which reported a doming of the heme plane. However, despite the high spin configuration of iron, the doming for ferric species is expected to be smaller than ferrous myoglobins. ${ }^{127}$ In fact, a minimisation including the Dom1 and Dom2 parameters (see the ESI $\dagger$ for a description of these parameters) yielded small values with large uncertainties $(0.02 \pm 0.06$ for both parameters) and therefore we conclude that the heme is not domed.

The pre-edge spectrum of metMb is shown in Fig. 7b. In contrast to the other forms of $\mathrm{Mb}$, the feature at $\sim 9 \mathrm{eV}$ is rather broad and weak. This difference is consistent with the structural fluctuations of $\mathrm{Fe}-\mathrm{O}$ associated with thermal motions, which would give rise to a spectral broadening. No broadening appears in the $\mathrm{L}_{2 / 3}$-edge spectra of Wang et al. ${ }^{39}$ because fluctuations of the $\mathrm{Fe}-\mathrm{O}$ distance will not significantly alter the $3 \mathrm{~d}$ character, which are the dipole allowed transitions for the $\mathrm{L}_{2 / 3}$-edges. However, they would be expected to alter the $\mathrm{Fe}$ $4 \mathrm{p}$ contribution, which as discussed for the previous spectra, plays an important role in the pre-edge intensities. Overall our simulations are in good agreement with the experiment, but the features are not as broad owing to the use of a single configuration (best fit) and therefore thermal motions are not replicated. We find that the feature corresponding to $\mathrm{A}^{\mathrm{l}}$ is composed of three principal transitions, which are separated by less than the experimental broadening and therefore appear as one feature. The first two, separated by $1 \mathrm{eV}$ are the $1 \mathrm{~s} \rightarrow \mathrm{d}_{\pi}$ and $1 \mathrm{~s} \rightarrow \mathrm{d}_{\sigma}$ transitions due to the high spin state of iron and are consistent with features in the $\mathrm{L}_{2 / 3}$-edges of Wang et al. ${ }^{39}$ The third transition, is very weak, has a $1 \mathrm{~s} \rightarrow \mathrm{d}_{\pi}+\pi_{\text {Porphyrin }}{ }^{*}$ character, and arises from the porphyrin $\pi$ donation due to the ferric oxidation state of iron in metMb. Finally, like MbCN, the edge position of metMb $(7126.2 \mathrm{eV}$, see Table $\mathrm{S} 1$, ESI $\dagger)$ means that the $1 \mathrm{~s} \rightarrow 4 \mathrm{p}$ transition is visible at $-7 \mathrm{eV}$, and in common with the lower energy feature, the thermal motions associated with the weak Fe-O bond imply that this feature is weaker than observed for $\mathrm{MbCN}$ and $\mathrm{MbO}_{2}$.

\section{6 deoxyMb}

DeoxyMb represents a unique case as the ferrous iron is not ligated resulting in a pentacoordination. In addition, the high

Table 5 Summary of literature results for metMb

\begin{tabular}{|c|c|c|c|c|c|c|c|}
\hline & This work & Ref. 124 & Ref. 53 & Ref. 125 & Ref. $33^{a}$ & Ref. 86 & Ref. 126 \\
\hline $\mathrm{Fe}-\mathrm{N}_{\mathrm{p}}[\AA]$ & $2.03 \pm 0.01$ & $2.04 \pm 0.02$ & $2.01 \pm 0.02$ & 2.04 & $2.03 \pm 2$ & 2.03 & 2.01 \\
\hline $\operatorname{Disp}[\AA]$ & $-0.07 \pm 0.02$ & - & - & - & $-0.138 \pm 0.004$ & - & - \\
\hline Dom1 [̊] & - & - & - & - & $-0.106 \pm 0.007$ & - & - \\
\hline Dom2 [A] & - & - & - & - & - & - & - \\
\hline $\mathrm{Fe}-\mathrm{Li}[\AA]$ & $2.31 \pm 0.05$ & $2.08 \pm 0.03$ & $2.22 \pm 0.06$ & 2.10 & $2.13 \pm 0.01$ & 2.17 & 2.29 \\
\hline$\alpha\left[{ }^{\circ}\right]$ & $16 \pm 4$ & - & - & - & 6.8 & - & - \\
\hline$\beta\left[^{\circ}\right]$ & - & - & - & - & - & - & - \\
\hline $\mathrm{Fe}-\mathrm{N}_{\varepsilon}[\AA]$ & $2.14 \pm 0.01$ & $2.16 \pm 0.02$ & $2.14 \pm 0.06$ & 2.12 & $2.14 \pm 0.01$ & 2.16 & 2.26 \\
\hline $\mathrm{L}_{1}-\mathrm{L}_{2}[\AA]$ & - & - & - & - & - & - & - \\
\hline Technique & XANES & XANES & XANES & EXAFS & Diffraction & Diffraction & Diffraction \\
\hline Mb source & Horse muscle & Horse heart & Sperm whale & - & Sperm whale & Sperm whale & Horse heart \\
\hline Temp. [K] & 298 & 10 & 15 & 260 & 90 & 287 & - \\
\hline PDB entry & - & - & - & - & $1 \mathrm{~A} 6 \mathrm{~K}$ & $1 \mathrm{BZ6}$ & 1YMB \\
\hline Res. [̊] & - & - & - & - & 1.10 & 1.20 & 1.90 \\
\hline$R$-value & - & - & - & - & 0.131 & 0.091 & 0.155 \\
\hline
\end{tabular}

${ }^{a}$ Input PDB structure for MXAN optimization. 
Table 6 Summary of literature results for deoxyMb

\begin{tabular}{|c|c|c|c|c|c|c|c|}
\hline & This work & Ref. $86^{a}$ & Ref. 33 & Ref. 46 & Ref. 88 & Ref. 124 & Ref. 51 \\
\hline $\mathrm{Fe}-\mathrm{N}_{\mathrm{p}}[\AA]$ & $2.075 \pm 0.009$ & 2.057 & $2.07 \pm 0.03$ & $2.06 \pm 0.03$ & $2.07 \pm 0.02^{b}$ & $2.06 \pm 0.02$ & $2.04 \pm 0.03$ \\
\hline Disp [Å] & $-0.20 \pm 0.02$ & -0.29 & $-0.390 \pm 0.006$ & $-0.2 \pm 0.2$ & - & - & - \\
\hline $\operatorname{Dom} 1[\AA]$ & $-0.03 \pm 0.01$ & - & -0.027 & - & - & - & - \\
\hline $\mathrm{Fe}-\mathrm{Li}[\AA]$ & - & - & - & - & - & - & \\
\hline$\alpha\left[{ }^{\circ}\right]$ & - & - & - & - & - & - & - \\
\hline$\beta\left[^{\circ}\right]$ & - & 28 & - & - & - & - & - \\
\hline Technique & XANES & Diffraction & Diffraction & XANES & EXAFS & XANES & XANES \\
\hline Mb source & Horse muscle & Sperm whale & Sperm whale & Horse heart & Sperm whale & Horse heart & Sperm whale \\
\hline Temp. [K] & 298 & 287 & 100 & 20 & 20 & 10 & 100 \\
\hline PDB entry & - & 1BZP & $1 \mathrm{~A} 6 \mathrm{~N}$ & - & - & - & - \\
\hline Res. $[\AA]$ & - & 1.15 & 1.15 & - & - & - & - \\
\hline$R$-value & - & 0.114 & 0.121 & - & - & - & - \\
\hline
\end{tabular}

${ }^{a}$ Input PDB structure for MXAN optimization. ${ }^{b}$ This EXAFS result was unable to distinguish between the porphyrin and proximal histidine $\mathrm{N}$ atoms.

spin state of iron leads to doming of the heme plane. However, the magnitude of the doming is difficult to quantify and many previous studies have reported an iron displacement from the heme plane $e^{46,51,128}$ which induces considerable strain on the bonds within the porphyrin (see Table 6). In these studies, the porphyrin ring size, given by the average distance $\mathrm{Fe}-\mathrm{N}_{\mathrm{p}}$, is found to have a consistent value, reflecting the rigidity of the structure. On the other hand, all the other structural parameters vary considerably outside the reported errors, suggesting that their values are affected by the fact of using crystals in the experiments or by a sample not consisting of deoxyMb only.

The fit of the experimental spectrum and the structural parameters are shown in Fig. 8 and Table 6, respectively. In our analysis, we find that the magnitude of the doming has a large influence on features $\mathrm{C}$ and $\mathrm{D}$, and its accurate description is therefore indispensable for a proper agreement between the experimental and the simulated spectrum (see ESI $\dagger$ for details). The best fit to the deoxyMb XAS spectrum was achieved with Disp $=0.2 \pm 0.02 \AA$, Dom $1=0.03 \pm 0.01 \AA$ and Dom $2=$ $0.04 \pm 0.01 \AA$ (see Fig. S3, ESI $\dagger$ ). The iron displacement is smaller than in previous reports (except ref. 46 which has a large uncertainty), but this is because our present model not only considers the distortion of the iron, but also the nitrogens and nearest carbons in the heme plane, providing a more physical description of the doming. Besides the doming, we find a significant difference between our $\mathrm{Fe}-\mathrm{N}_{\varepsilon}$ distance and most previously reported values. However, an EXAFS study by Rich et al. ${ }^{129}$ has reported a value of $2.31 \AA$ for $\mathrm{pH} 6$ and a temperature of $10 \mathrm{~K}$. This distance decreases when the $\mathrm{pH}$ is either increased or decreased, and therefore this bond in particular appears to be very sensitive to the experimental conditions. Given that our present conditions are $298 \mathrm{~K}$ and $\mathrm{pH} 7$, we believe that our structure is the most relevant to physiological conditions.

The experimental and calculated pre-edge spectra of deoxyMb are shown in Fig. 8b. We observe one pre-edge peak, shifted (on the absolute energy scale in Fig. 2) by $3 \mathrm{eV}$ to lower energies. The high spin confirmation means that $1 \mathrm{~s} \rightarrow \mathrm{d}_{\pi}$, as well as
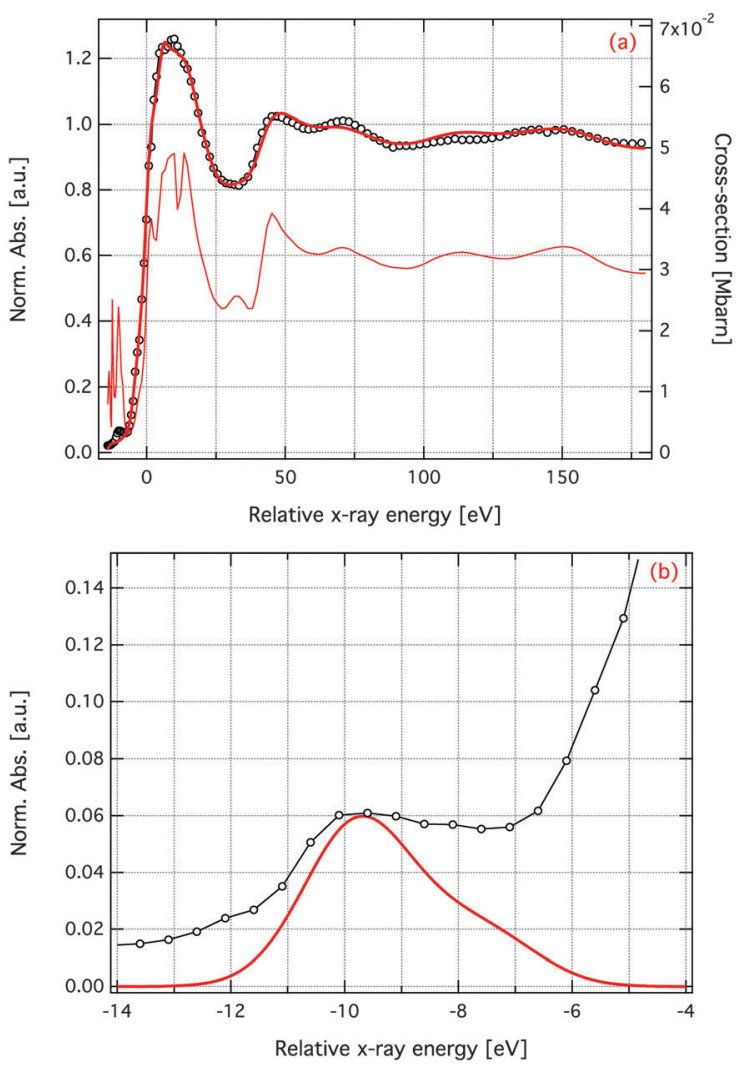

Fig. 8 MXAN best fit of the XAS spectrum of deoxyMb (a) and the preedge spectrum calculated using TD-DFT within the approximation of the BP86 functional (b). Details of the calculations are given in the ESI. $\dagger$ The experimental data are represented by open circles. In (a) the calculated total cross-section, i.e. unconvoluted with respect to the lifetime broadening function, is represented by the thin solid line (right axis). The energy scale used in the fits is relative to the position of the first derivative of the XAS spectra, which is a first guess of the $E_{0}$ - see Table S1 (ESI $\dagger$ ).

$1 \mathrm{~s} \rightarrow \mathrm{d}_{\sigma}$ should be accessible. Our simulations contained both transitions, which are separated by $\sim 1.5 \mathrm{eV}$, in agreement with the $\mathrm{L}_{2 / 3}$-edge spectra of Wang et al. ${ }^{39}$ This separation is smaller 
than our present resolution and therefore they appear as one peak, for which the $1 \mathrm{~s} \rightarrow \mathrm{d}_{\pi}$ transitions are very weak because they arise from the quadrupole moment, in contrast to the 1s $\rightarrow d_{\sigma}$, which as discussed above has a significant $4 \mathrm{p}$ mixing and therefore a dipole component.

\section{Conclusion}

We have investigated the electronic and geometric structure of six different forms of $\mathrm{Mb}$ under physiological conditions using Fe K-edge X-ray absorption spectroscopy. The geometric analysis of the XANES region of the spectrum, using the FMS formalism, reveals that the iron-nitrogen bond length in the porphyrin rings of the different forms of $\mathrm{Mb}$ converge to a common value of about $2 \AA$, in contrast to the wide variation found in the crystallographic structures. This reflects the relative rigidity of the porphyrin, due to the many carbon-carbon double bounds. The $\mathrm{Fe}-\mathrm{N}_{\varepsilon}$ bond length demonstrates a trend associated with the effect of ligand binding. The binding of $\mathrm{CO}, \mathrm{O}_{2}$ and $\mathrm{CN}$ is known to strengthen the $\mathrm{Fe}-\mathrm{N}_{\varepsilon}$ bond, and in agreement with this we find a significantly shorter bond length than the corresponding one in deoxyMb. In contrast, NO hemes are known to exhibit a strong trans effect, ${ }^{105}$ which reduces the strength of the $\mathrm{Fe}-\mathrm{N}_{\varepsilon}$ bond. Although, we find that it is still stronger than in deoxyMb, the $\mathrm{Fe}-\mathrm{N}_{\varepsilon}$ is larger than that in the other ligated myoglobins. For metMb, the weakly bound water molecule slightly strengthens the $\mathrm{Fe}-\mathrm{N}_{\varepsilon}$ bond and the bond length is similar to that of MbNO. The bonding angles of the various ligands, defined using the $\alpha$ and $\beta$ angles, which play an important role in the exit trajectory of the ligand following photodissociation are found to agree largely with previous crystallographic and XAS refinements.

The electronic structure of the different forms of Mbs was investigated by simulating the pre-edge features using TD-DFT. These features for all forms of $\mathrm{Mb}$ are predominately $1 \mathrm{~s} \rightarrow \mathrm{d}_{\sigma}$ and $1 \mathrm{~s} \rightarrow \mathrm{d}_{\pi}-\pi_{\text {ligand }}{ }^{*}$ transitions, while $1 \mathrm{~s} \rightarrow \mathrm{d}_{\pi}$ transitions also weakly contribute for $\mathrm{MbO}_{2}$, metMb and deoxyMb. Importantly, despite their molecular orbitals being dominated by the Fe d-character, these transitions draw intensity via the dipole transition moment, due to the low symmetry environment around the heme which makes $3 \mathrm{~d}-4 \mathrm{p}$ mixing symmetry allowed. This mixing, owing to the lack of centrosymmetric symmetry, occurs in all Mbs presented here and the intensity of the pre-edge features form two distinct classes; (i) stronger for MbNO and MbCO and (ii) weaker for $\mathrm{MbO}_{2}$ and $\mathrm{MbCN}$. Previous XAS investigations have demonstrated that the magnitude of $\mathrm{Fe} 3 \mathrm{~d}-4 \mathrm{p}$ mixing is sensitive to the Fe-X bond length. ${ }^{97}$ This is the case here, as both MbNO and MbCO have, following our present refinement $\mathrm{Fe}-\mathrm{X}$ of $\sim 1.8 \AA$, while the latter $\left(\mathrm{MbO}_{2}\right.$ and $\left.\mathrm{MbCN}\right)$ are $\sim 1.9 \AA$. Importantly, this further confirms our assignment of the $\mathrm{Fe}-\mathrm{O}$ bond length, which is approximately $0.1 \AA$ A longer than previous assignments.

In conclusion, this study represents an important development towards the study of the electronic and geometrical structure of biological systems and, in particular, the dynamics of ligand rebinding in heme proteins using time-resolved XAS. In addition, the consistent experimental and theoretical treatment of the whole myoglobin series means that we avoid systematic errors in the structural refinement. Importantly, the results are derived from measurements taken in physiological flowing solutions, which minimises the X-ray-induced reduction, lysis or damage and because of the physiological solutions, our data are also not biased by crystal packing forces and/or stress. Despite this our results have demonstrated that in general the structural parameters reported are largely in agreement with the most recent refinements using X-ray crystallographic data. Finally, the presented methodology can be extended to the study of other biological systems, providing experimental conditions closer to the ones found during biochemical reactions.

\section{Acknowledgements}

This work was funded by the Swiss NSF through the NCCR MUST 'Molecular ultrafast science and technology' and contracts 200020/ 12723, 200020/116334, 200020/117401 and by the SBF via the COST action CM0702 and D35. We thank S. Karlsson, A. El Nahhas and D. Chiranthika and the MicroXas beamline team for their assistance during the measurements.

\section{References}

1 K. R. Rodgers, Curr. Opin. Chem. Biol., 1999, 3, 158-167.

2 T. G. Spiro and A. A. Jarzecki, Curr. Opin. Chem. Biol., 2001, 5, 715-723.

3 E. Antonini and M. Brunori, Hemoglobin and Myoglobin in their Reactions with Ligands, North-Holland Pub. Co., 1971.

4 U. B. Hendgen-Cotta, U. Flögel, M. Kelm and T. Rassaf, J. Exp. Biol., 2010, 213, 2734-2740.

5 U. Flögel, M. W. Merx, A. Gödecke, U. K. M. Decking and J. Schrader, Proc. Natl. Acad. Sci. U. S. A., 2001, 98, 735-740.

6 M. Brunori, Trends Biochem. Sci., 2001, 26, 21-23.

7 M.-S. Liao, M.-J. Huang and J. D. Watts, J. Mol. Model, 2013, 19, 3307-3323.

8 F. De Angelis, A. A. Jarzecki, R. Car and T. G. Spiro, J. Phys. Chem. B, 2005, 109, 3065-3070.

9 J. Bertran, M. F. Ruiz-Lopez and D. Rinaldi, THEOCHEM, 1991, 232, 337-347.

10 J. P. Collman and L. Fu, Acc. Chem. Res., 1999, 32, 455-463.

11 C. Rovira, THEOCHEM, 2003, 632, 309-321.

12 B. A. Springer, S. G. Sligar, J. S. Olson and G. N. J. Phillips, Chem. Rev., 1994, 94, 699-714.

13 A. Ansari, J. Berendzen, D. Braunstein, B. R. Cowen, H. Frauenfelder, M. K. Hong, I. E. T. Iben, J. B. Johnson, P. Ormos and T. B. Sauke, Biophys. Chem., 1987, 26, 337-355.

14 J. W. Petrich, J. C. Lambry, K. Kuczera, M. Karplus, C. Poyart and J. L. Martin, Biochemistry, 1991, 30, 3975-3987.

15 P. J. Steinbach, A. Ansari, J. Berendzen, D. Braunstein, K. Chu, B. R. Cowen, D. Ehrenstein, H. Frauenfelder and J. B. a. Johnson, Biochemistry, 1991, 30, 3988-4001.

16 L. Miller and M. Chance, Biochemistry, 1995, 34, 10170-10179.

17 L. M. Miller and M. R. Chance, J. Am. Chem. Soc., 1994, 116, 9662-9669. 
18 D. L. Rousseau and P. V. Argade, Proc. Natl. Acad. Sci. U. S. A., 1986, 83, 1310-1314.

19 M. H. Lim, T. A. Jackson and P. A. Anfinrud, Nat. Struct. Biol., 1997, 4, 209-214.

20 J. L. Martin and M. H. Vos, Annu. Rev. Biophys. Biomol. Struct., 1992, 21, 199-222.

21 J.-L. Martin and M. Vos, Methods Enzymol., 1994, 232, 416-430.

22 M. Vos, Biochim. Biophys. Acta, Bioenerg., 2008, 1777, 15-31.

23 P. M. Champion, F. Rosca, D. Ionascu, W. Cao and X. Ye, Faraday Discuss., 2004, 217, 123-135.

24 W. Wang, A. Demidov, X. Ye, J. F. Christian, T. Sjodin and P. M. Champion, J. Raman Spectrosc., 2000, 31, 99-105.

25 D. M. Mills, A. Lewis, A. Harootunian, J. Huang and B. Smith, Science, 1984, 223, 811-813.

26 J. W. Petrich, J. L. Martin, D. Houde, C. Poyart and A. Orszag, Biochemistry, 1987, 26, 7914-7923.

27 A. Stickrath, M. Mara, J. Lockard, M. Harpham, J. Huang, X. Zhang, K. Attenkofer and L. Chen, J. Phys. Chem. B, 2013, 117, 4705-4712.

28 D. Bourgeois, T. Ursby, M. Wulff, C. Pradervand, A. Legrand, W. Schildkamp, S. Labouré, V. Srajer, T. Y. Teng, M. Roth and K. Moffat, J. Synchrotron Radiat., 1996, 3, 65-74.

29 V. Arajer and W. Royer Jr, Time-Resolved X-Ray Crystallography of Heme Proteins, Academic Press, 2008, vol. 437, pp. 379-395.

30 D. Bourgeois, B. Vallone, F. Schotte, A. Arcovito, A. E. Miele, G. Sciara, M. Wulff, P. Anfinrud and M. Brunori, Proc. Natl. Acad. Sci. U. S. A., 2003, 100, 8704-8709.

31 F. Schotte, M. Lim, T. A. Jackson, A. V. Smirnov, J. Soman, J. S. Olson, G. N. Phillips Jr, M. Wulff and P. A. Anfinrud, Science, 2003, 300, 1944-1947.

32 R. Aranda, E. Levin, F. Schotte, P. Anfinrud and G. Phillips, Acta Crystallogr., Sect. D: Biol. Crystallogr., 2006, 62, 776-783.

33 J. Vojtchovsky, K. Chu, J. Berendzen, R. Sweet and I. Schlichting, Biophys. J., 1999, 77, 2153-2174.

34 M. Sono, M. P. Roach, E. D. Coulter and J. H. Dawson, Chem. Rev., 1996, 96, 2841-2888.

35 S. A. Wilson, T. Kroll, R. A. Decreau, R. K. Hocking, M. Lundberg, B. Hedman, K. O. Hodgson and E. I. Solomon, J. Am. Chem. Soc., 2013, 135, 1124-1136.

36 G. Bunker, Introduction to XAFS: A practical guide to X-ray absorption fine structure, Cambridge University Press, 2010.

37 J. Stöhr, NEXAFS Spectroscopy, Springer, 1996, vol. 25.

38 T. Penfold, C. Milne and M. Chergui, Adv. Chem. Phys., 2013, 153, 1-41.

39 H. Wang, G. Peng, L. M. Miller, E. M. Scheuring, S. J. George, M. R. Chance and S. P. Cramer, J. Am. Chem. Soc., 1997, 119, 4921-4928.

40 E. F. Aziz, N. Ottosson, S. Bonhommeau, N. Bergmann, W. Eberhardt and M. Chergui, Phys. Rev. Lett., 2009, 102, 068103.

41 E. Aziz, H. Rittmann-Frank, K. Lange, S. Bonhommeau and M. Chergui, Nat. Chem., 2010, 2, 853-857.
42 K. M. Lange, R. Golnak, S. Bonhommeau and E. F. Aziz, Chem. Commun., 2013, 49, 4163-4165.

43 R. G. Shulman, P. Eisenberger and B. M. Kincaid, Annu. Rev. Biophys. Bioeng., 1978, 7, 559-578.

44 M. R. Chance, L. M. Miller, R. F. Fischetti, E. Scheuring, W. X. Huang, B. Sclavi, Y. Hai and M. Sullivan, Biochemistry, 1996, 35, 9014-9023.

45 A. Arcovito, D. C. Lamb, G. U. Nienhaus, J. L. Hazemann, M. Benfatto and S. D. Longa, Biophys. J., 2005, 88, 2954-2964.

46 P. D’Angelo, A. Lapi, V. Migliorati, A. Arcovito, M. Benfatto, O. Roscioni, W. Meyer-Klaucke and S. Della-Longa, Inorg. Chem., 2008, 47, 9905-9918.

47 S. Della-Longa, A. Arcovito, M. Girasole, J. L. Hazemann and M. Benfatto, Phys. Rev. Lett., 2001, 87, 155501.

48 S. Della-Longa, A. Arcovito, B. Vallone, A. C. Castellano, R. Kahn, J. Vicat, Y. Soldo and J. L. Hazemann, J. Synchrotron Radiat., 1999, 6, 1138-1147.

49 S. D. Longa and A. Arcovito, Inorg. Chem., 2010, 49, 9958-9961.

50 A. Arcovito, M. Benfatto, M. Cianci, S. S. Hasnain, K. Nienhaus, G. U. Nienhaus, C. Savino, R. W. Strange, B. Vallone and S. D. Longa, Proc. Natl. Acad. Sci. U. S. A., 2007, 104, 6211-6216.

51 A. Arcovito, C. Ardiccioni, M. Cianci, P. D’Angelo, B. Vallone and S. D. Longa, J. Phys. Chem. B, 2010, 114, 13223-13231.

52 N. Bergmann, S. Bonhommeau, K. Lange, S. Greil, S. Eisebitt, F. de Groot, M. Chergui and E. Aziz, Phys. Chem. Chem. Phys., 2010, 12, 4827-4832.

53 S. Della-Longa, A. Arcovito, M. Benfatto, A. CongiuCastellano, M. Girasole, J. L. Hazemann and A. L. Bosco, Biophys. J., 2003, 85, 549-558.

54 M. Cammarata, M. Levantino, F. Schotte, P. A. Anfinrud, F. Ewald, J. Choi, A. Cupane, M. Wulff and H. Ihee, Nat. Methods, 2008, 5, 881-886.

55 H. S. Cho, N. Dashdorj, F. Schotte, T. Graber, R. Henning and P. Anfinrud, Proc. Natl. Acad. Sci. U. S. A., 2010, 107, 7281-7286.

56 F. Lima, C. Milne, D. Amarasinghe, M. Rittmann-Frank, R. van der Veen, M. Reinhard, V.-T. Pham, S. Karlsson, S. Johnson, D. Grolimund, C. Borca, T. Huthwelker, M. Janousch, F. van Mourik, R. Abela and M. Chergui, Rev. Sci. Instrum., 2011, 82, 063111.

57 M. Benfatto, C. Natoli, A. Bianconi, J. Garcia, A. Marcelli, M. Fanfoni and I. Davoli, Phys. Rev. B: Condens. Matter. Mater. Phys., 1986, 34, 5774.

58 M. Benfatto, A. Congiu-Castellano, A. Daniele and S. D. Longa, J. Synchrotron Radiat., 2001, 8, 267-269.

59 M. Benfatto, S. D. Longa and C. Natoli, J. Synchrotron Radiat., 2003, 10, 51-57.

60 M. Benfatto and S. D. Longa, J. Phys.: Conf. Ser., 2009, 190, 1-4.

61 S. Debeer-George, T. Petrenko and F. Neese, Inorg. Chim. Acta, 2008, 361, 965-972.

62 S. DeBeer-George, T. Petrenko and F. Neese, J. Phys. Chem. A, 2008, 112, 12936-12943. 
63 F. Neese, Wiley Interdiscip. Rev.: Comput. Mol. Sci., 2012, 2, 73-78.

64 F. Neese, Inorg. Chim. Acta, 2002, 337, 181-192.

65 V. Pham, I. Tavernelli, C. Milne, R. van der Veen, P. D'Angelo, C. Bressler and M. Chergui, Chem. Phys, 2010, 371, 24-29.

66 R. van der Veen, J. Kas, C. Milne, V.-T. Pham, A. Nahhas, F. Lima, D. Vithanage, J. Rehr, R. Abela and M. Chergui, Phys. Chem. Chem. Phys., 2010, 12, 5551-5561.

67 A. El Nahhas, R. M. van der Veen, T. J. Penfold, V. T. Pham, F. A. Lima, R. Abela, A. M. Blanco-Rodriguez, S. Zalis, A. Vlcek, U. Tavernelli, I. Rothlisberger, C. J. Milne and M. Chergui, J. Phys. Chem. A, 2013, 117, 361-369.

68 S. Della-Longa, I. Ascone, A. Fontaine, A. C. Castellano and A. Bianconi, Eur. Biophys. J., 1994, 23, 361-368.

69 R. K. Hocking, E. C. Wasinger, Y.-L. Yan, F. M. F. deGroot, F. A. Walker, K. O. Hodgson, B. Hedman and E. I. Solomon, J. Am. Chem. Soc., 2007, 129, 113-125.

70 M. W. Makinen, R. A. Houtchens and W. S. Caughey, Proc. Natl. Acad. Sci. U. S. A., 1979, 76, 6042-6046.

71 G. U. Nienhaus, J. R. Mourant and H. Frauenfelder, Proc. Natl. Acad. Sci. U. S. A., 1992, 89, 2902-2906.

72 J. N. Moore, P. A. Hansen and R. M. Hochstrasser, Proc. Natl. Acad. Sci. U. S. A., 1988, 85, 5062-5066.

73 M. Lim, T. A. Jackson and P. A. Anfinrud, J. Am. Chem. Soc., 2004, 126, 7946-7957.

74 M. Lim, T. A. Jackson and P. A. Anfinrud, J. Phys. Chem., 1996, 100, 12043-12051.

75 M. Lim and P. Anfinrud, Methods Mol. Biol., 2005, 305, 243-259.

76 M. Lim, T. Jackson and P. Anfinrud, Proc. Natl. Acad. Sci. U. S. A., 1993, 90, 5801-5804.

77 T.-Y. Teng and H. W. Huang, Biochim. Biophys. Acta, Protein Struct. Mol. Enzymol., 1986, 874, 13-18.

78 T.-y. Teng, H. W. Huang and G. A. Olah, Biochemistry, 1987, 26, 8066-8072.

79 T. Y. Teng, V. Srajer and K. Moffat, Nat. Struct. Biol., 1994, 1, 701-705.

80 V. Srajer, T. Teng, T. Ursby, C. Pradervand and Z. Ren, Science, 1996, 274, 1726-1729.

81 T.-Y. Teng, V. Srajer and K. Moffat, Biochemistry, 1997, 36, 12087-12100.

82 V. Srajer, Z. Ren, T. Teng, M. Schmidt and T. Ursby, Biochemistry, 2001, 40, 13802-13815.

83 D. Bourgeois, B. Vallone, A. Arcovito, G. Sciara, F. Schotte, P. Anfinrud and M. Brunori, Proc. Natl. Acad. Sci. U. S. A., 2006, 103, 4924-4929.

84 R. F. Service, Science, 1995, 269, 921-922.

85 B. D. Dunietz, A. Dreuw and M. Head-Gordon, J. Phys. Chem. B, 2003, 107, 5623-5629.

86 G. S. Kachalova, A. N. Popov and H. D. Bartunik, Science, 1999, 284, 473-476.

87 J. Kuriyan, S. Wilz, M. Karplus and G. A. Petsko, J. Mol. Biol., 1986, 192, 133-154.

88 K. Zhang, K. S. Reddy, G. Bunker and B. Chance, Proteins: Struct., Funct., Bioinf., 1991, 10, 279-286.
89 A. D. Becke, Phys. Rev. A, 1988, 38, 3098-3100.

90 C. Lee, W. Yang and R. G. Parr, Phys. Rev. B: Condens. Matter. Mater. Phys., 1988, 37, 785-789.

91 S. H. Vosko, L. Wilk and M. Nusair, Can. J. Phys., 1980, 58, 1200-1211.

92 M. Reiher, O. Salomon and B. Artur Hess, Theor. Chem. Acc., 2001, 107, 48-55.

93 G. Capano, T. Penfold, N. Besley, C. Milne, M. Reinhard, H. Rittmann-Frank, P. Glatzel, R. Abela, U. Rothlisberger, M. Chergui and I. Tavernelli, Chem. Phys. Lett., 2013, 580, 179-184.

94 J. P. Perdew, Phys. Rev. B: Condens. Matter. Mater. Phys., 1986, 33, 8822-8824.

95 H. Wang, G. Peng and S. Cramer, J. Electron Spectrosc. Relat. Phenom., 2005, 143, 1-7.

96 J. N. Harvey, Annu. Rep. Prog. Chem., Sect. C: Phys. Chem., 2006, 102, 203-226.

97 T. Westre, P. Kennepohl, J. DeWitt, B. Hedman, K. Hodgson and E. Solomon, J. Am. Chem. Soc., 1997, 119, 6297-6314.

98 C. Coyle, K. Vogel, T. Rush, P. Kozlowski, R. Williams, T. Spiro, Y. Dou, M. Ikeda-Saito, J. Olson and M. Zgierski, Biochemistry, 2003, 42, 4896-4903.

99 T. Zemojtel, M. Rini, K. Heyne, T. Dandekar, E. T. J. Nibbering and P. M. Kozlowski, J. Am. Chem. Soc., 2004, 126, 1930-1931.

100 A. Rich, R. Armstrong, P. Ellis and P. Lay, J. Am. Chem. Soc., 1998, 120, 10827-10836.

101 K. M. Vogel, P. M. Kozlowski, M. Z. Zgierski and T. G. Spiro, J. Am. Chem. Soc., 1999, 121, 9915-9921.

102 D. Copeland, A. West and G. Richter-Addo, Proteins, 2003, 53, 182-192.

103 D. Copeland, A. Soares, A. West and G. Richter-Addo, J. Inorg. Biochem., 2006, 100, 1413-1425.

104 E. Brucker, J. Olson, M. Ikeda-Saito and G. Phillips, Proteins: Struct., Funct., Bioinf., 1998, 30, 352-356.

105 S. M. Decatur, S. Franzen, G. D. DePillis, R. B. Dyer, W. H. Woodruff and S. G. Boxer, Biochemistry, 1996, 35, 4939-4944.

106 M. Sundararajan and F. Neese, J. Chem. Theory Comput., 2012, 8, 563-574.

107 S. M. Decatur, K. L. Belcher, P. K. Rickert, S. Franzen and S. G. Boxer, Biochemistry, 1999, 38, 11086-11092.

108 S. E. V. Phillips, J. Mol. Biol., 1980, 142, 531-554.

109 L. Powers, J. L. Sessler, G. L. Woolery and B. Chance, Biochemistry, 1984, 23, 5519-5523.

110 M. Unno, H. Chen, S. Kusama, S. Shaik and M. Ikeda-Saito, J. Am. Chem. Soc., 2007, 129, 13394-13395.

111 S. Phillips and B. Schoenborn, Nature, 1981, 292, 81-82.

112 J. A. Lukin, V. Simplaceanu, M. Zou, N. T. Ho and C. Ho, Proc. Natl. Acad. Sci. U. S. A., 2000, 97, 10354-10358.

113 C. D. C. Linus Pauling, Proc. Natl. Acad. Sci. U. S. A., 1936, 22, 210.

114 J. J. Weiss, Nature, 1964, 203, 183.

115 W. A. Goddard and B. D. Olafson, Proc. Natl. Acad. Sci. U. S. A., 1975, 72, 2335-2339.

116 H. Chen, M. Ikeda-Saito and S. Shaik, J. Am. Chem. Soc., 2008, 130, 14778-14790. 
117 S. A. Wilson, E. Green, I. I. Mathews, M. Benfatto, K. O. Hodgson, B. Hedman and R. Sarangi, Proc. Natl. Acad. Sci. U. S. A., 2013, 110, 16333-16338.

118 J. Helbing, L. Bonacina, R. Pietri, J. Bredenbeck, P. Hamm, F. van Mourik, F. Chaussard, A. Gonzalez-Gonzalez, M. Chergui, C. Ramos-Alvarez, C. Ruiz and J. LopezGarriga, Biophys. J., 2004, 87, 1881-1891.

119 F. Gruia, M. Kubo, X. Ye and P. M. Champion, Biophys. J., 2008, 94, 2252-2268.

120 R. Schweitzer-Stenner, A. Cupane, M. Leone, C. Lemke, J. Schott and W. Dreybrodt, J. Phys. Chem. B, 2000, 104, 4754-4764.

121 M. Bolognesi, C. Rosano, R. Losso, A. Borassi, M. Rizzi, J. B. Wittenberg, A. Boffi and P. Ascenzi, Biophys. J., 1999, 77, 1093-1099.
122 T. Tanaka, N. T. Yu and C. K. Chang, Biophys. J., 1987, 52, 801.

123 T. Kitagawa, Y. Kyogoku, T. Iizuka and M. I. Saito, J. Am. Chem. Soc., 1976, 98, 5169-5173.

124 M. Cheng, A. Rich, R. Armstrong, P. Ellis and P. Lay, Inorg. Chem., 1999, 38, 5703-5708.

125 C. Scherk, A. Ostermann, K. Achterhold, O. Iakovleva, C. Nazikkol, B. Krebs, E. Knapp, W. Meyer-Klaucke and F. Parak, Eur. Biophys. J., 2001, 30, 393-403.

126 S. V. Evans and G. D. Brayer, J. Mol. Biol., 1990, 213, 885-897.

127 S. Franzen, B. Bohn, C. Poyart, G. DePillis, S. G. Boxer and J.-L. Martin, J. Biol. Chem., 1995, 270, 1718-1720.

128 A. Arcovito, M. Benfatto, P. D'Angelo and S. D. Longa, AIP Conference Proceedings-XAFS13, 2007, 882, 306-310.

129 A. Rich, R. Armstrong, P. Ellis and H. Freeman, Inorg. Chem., 1998, 37, 5743-5753. 